\title{
Monsoonal precipitation over Peninsular Malaysia in the CMIP6 HighResMIP experiments: the role of model resolution
}

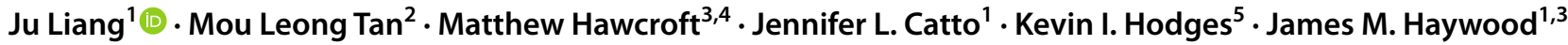

Received: 21 July 2021 / Accepted: 28 October 2021 / Published online: 12 November 2021

(c) The Author(s) 2021

\begin{abstract}
This study investigates the ability of 20 model simulations which contributed to the CMIP6 HighResMIP to simulate precipitation in different monsoon seasons and extreme precipitation events over Peninsular Malaysia. The model experiments utilize common forcing but are run with different horizontal and vertical resolutions. The impact of resolution on the models' abilities to simulate precipitation and associated environmental fields is assessed by comparing multi-model ensembles at different resolutions with three observed precipitation datasets and four climate reanalyses. Model simulations with relatively high horizontal and vertical resolution exhibit better performance in simulating the annual cycle of precipitation and extreme precipitation over Peninsular Malaysia and the coastal regions. Improvements associated with the increase in horizontal and vertical resolutions are also found in the statistical relationship between precipitation and monsoon intensity in different seasons. However, the increase in vertical resolution can lead to a reduction of annual mean precipitation compared to that from the models with low vertical resolutions, associated with an overestimation of moisture divergence and underestimation of lower-tropospheric vertical ascent in the different monsoon seasons. This limits any improvement in the simulation of precipitation in the high vertical resolution experiments, particularly for the Southwest monsoon season.
\end{abstract}

Keywords CMIP6 HighResMIP · Precipitation · Peninsular Malaysia · Model resolution

\section{Introduction}

The climate of Peninsular Malaysia is dominated by the annual precipitation cycle, which includes two monsoon seasons. As is typical for the wider western Maritime Continent region, during boreal winter (November-February, NDJF), a warm, moist atmosphere near the surface combines with intense horizontal moisture transport associated with the Northeast monsoon to produce strong convective

Ju Liang

J.Liang@exeter.ac.uk

1 College of Engineering, Mathematics and Physical Sciences, University of Exeter, Exeter EX4 4QE, UK

2 GeoInformatic Unit, Geography Section, School of Humanities, Universiti Sains Malaysia, 11800 USM Pulau Pinang, Malaysia

3 Met Office, Exeter EX1 3PB, UK

4 University of Southern Queensland, Toowoomba, QLD 4300, Australia

5 Department of Meteorology, University of Reading, Reading RG6 6ET, UK precipitation (Chang et al. 2005). Peninsular Malaysia is significantly influenced by precipitation extremes (e.g. Tangang et al. 2017) and associated flooding (e.g. Diya et al. 2014; Chan 2015). These climate extremes can cause considerable economic losses, casualties and a deterioration of the environment (Mohd et al. 2006; Muqtada et al. 2014), posing a great threat to livelihoods and thus limiting economic growth. During the past 40 years, the observed rainfall record indicates a considerable increasing trend in the annual total precipitation over Peninsular Malaysia (Mayowa et al. 2015). An increasing trend in the frequency of extreme rainfall events has also been observed in Peninsular Malaysia (Syafrina et al. 2014; Chan 1997; 2015; Mayowa et al. 2015).

Given these trends, it is important to understand likely future changes in precipitation in the region given the impact further increases in total and extreme precipitation could have on society and the environment. Climate models provide a key tool to provide a physically-based assessment of prospective impacts and risks from changing hydrological extremes, which in turn help to inform strategies of disaster mitigation and adaptation in a changing climate. Many 
studies have examined the simulation of precipitation over Peninsular Malaysia (e.g. Syafrina et al. 2014; Tan et al. 2014; Noor et al. 2019; Salman et al. 2020) and the adjacent areas in Southeast Asia (Siew et al. 2014; Raghavan et al. 2018; Tan et al. 2017; Kamworapan and Surussavadee 2019) using global climate models (GCMs). However, these studies document considerable biases in the modelled regional precipitation patterns compared to observed precipitation. One possible reason for this is the limited horizontal resolution (with grid spacing $>100 \mathrm{~km}$ ) of typical GCMs that makes it difficult to properly resolve the complex topography over the Maritime Continent and its interactions with the monsoon circulation (Chang et al. 2005). Coarse horizontal resolutions also lead to poorly resolved synoptic/mesoscale processes that are strongly associated with precipitation extremes in Peninsular Malaysia, such as Borneo Vortices (Tangang et al. 2008; Koseki et al. 2014; Liang et al. 2021) and easterly wave disturbances (Chen et al. 2013). Moreover, poor performance in simulating the eastward Kelvin wave activity coupled with equatorial convection has been demonstrated by GCMs with a horizontal resolution coarser than 50-km (Yang et al. 2009), which can limit the realism of simulated precipitation in the tropics.

The role of model horizontal resolution in the simulation of global precipitation is summarized by the study of Rauscher et al. (2016). They argued that fine horizontal resolutions are important for a model to capture intense precipitation because finer grid spacings can allow the precipitation-related vertical ascent to be further strengthened by the interaction between the constraint of fluid continuity and the emergent scaling properties of winds. In addition, a sufficiently high vertical resolution is important for modelling the vertical profile of cumulus latent heating rates, which are closely associated with tropical deep convection and the associated precipitation (Druyan et al. 2008; Rashid and Hirst 2017). Inness et al. (2001) suggested that a relatively coarse vertical resolution can lead to underestimates of sub-seasonal precipitation variability associated with the Madden Julian Oscillation due to the poorly resolved vertical distribution of convective cloud-top height. In the Asian monsoon region, Richter et al. (2014) reported that a GCM with relatively coarse vertical resolution tends to simulate a stronger summer monsoon and associated precipitation. Models with finer vertical resolutions also exhibit a better representation of the vertical profiles of water vapor and temperature (Tompkins and Emanuel 2000), which are closely associated with precipitation intensity (Fujita and Sato 2017).

Previous studies have attempted to improve model performance by downscaling GCM simulations over Peninsular Malaysia using statistical (Juneng et al. 2010; Nadrah and Tukimat 2011; Hassan et al. 2015) and dynamical (Tangang et al. 2013; 2020; Kwan et al. 2014; Amin et al. 2017; Chin and Tan 2018 2018; Jamaluddin et al. 2018; Ngai et al. 2020) downscaling. Although statistical downscaling is computationally cheap, it is dependent on the observational data at the target resolution used within the statistical model to be statistically correlated with the large-scale predictors. This process can be affected by uncertainties in both the observational data (e.g. Kotsuki and Tanaka 2013; Tan et al. 2015; Qi et al. 2016) and GCM performance (San-Martín et al. 2017). Dynamical downscaling using regional climate models (RCMs) is another important approach to increase resolutions as the limited area simulation of RCMs can reach higher resolution levels compared to GCMs for given computational resources (Demory et al. 2020). However, RCMs also exhibit considerable uncertainties in simulating precipitation over Southeast Asia (e.g. Nguyen-Thuy et al. 2021; Tangang et al. 2020) as the performance of RCMs is dependent on both the RCM configuration and the lateral boundary conditions from GCMs.

In recent years, high-resolution GCM simulations (with grid spacings $<50 \mathrm{~km}$ ) have been used in precipitation studies and have exhibited an improved ability in representing the observed regional precipitation patterns compared to coarse-resolution GCMs (e.g. Iorio et al. 2004; Mo et al. 2005; Sato et al. 2009; Feng et al. 2011; Kopparla et al. 2013; Yashiro et al. 2016; Kim et al. 2019; Bador et al. 2020; Kong et al. 2020). For instance, Arakawa and Kitoh (2005) and Sato et al. (2009) showed the improved ability of GCMs to represent the detailed topography and simulations of landsea breezes and the associated diurnal cycle of precipitation when finer horizontal resolutions are used. GCMs with finer horizontal resolution have also been shown to be capable of producing improved simulations of the interaction between the sea surface and the troposphere, which are important for realistic simulations of deep convection and associated precipitation (Scher et al. 2017). In Peninsular Malaysia, the precipitation patterns are associated with multiple physical factors that may be sensitive to changes in model resolution, such as complex synoptic systems (Chen et al. 2013; Koseki et al. 2014) and atmosphere-topographic interactions during the different monsoon seasons (Chang et al. 2005; Varikoden et al. 2010; 2011). However, there has been little research on the impact of increased horizontal and vertical resolution on GCM-simulated precipitation over the region.

The availability of high-resolution GCM data from the High Resolution Model Intercomparison Project (HighResMIP, Haarsma et al. 2016) of Coupled Model Intercomparison Project Phase 6 (CMIP6) provides a good opportunity to study the impact of model resolution on GCM simulations of precipitation. For instance, a recent study by Xin et al. (2021) evaluated the ability of the HighResMIP models to simulate precipitation in China and found improved simulation of precipitation in simulations at finer horizontal resolution due to the better resolved topographical 
rainfall. Molteni et al. (2020) has demonstrated the ability of the HighResMIP models to simulate the tropical Indo-Pacific rainfall and its modulations by the El Niño-Southern Oscillation (ENSO) and the North Atlantic Oscillation. Their study found that most of the HighResMIP GCMs simulate the late-winter ENSO teleconnection reasonably well; however, it is difficult to detect a consistent change in the realism of the simulated atmospheric teleconnections when model resolution is increased. Ajibola et al. (2020) assessed the ability of the HighResMIP GCMs to simulate West African summer monsoon rainfall and suggested limited improvements in simulated mean precipitation when GCM simulations at finer horizontal resolution are compared with those at coarser resolution. For these studies of precipitation simulations based on HighResMIP, three main limitations are noted in the model evaluation process. First, the role of vertical resolution in precipitation simulation is usually ignored. Second, the validation data used to assess model performance is usually based on a single dataset, which may bring considerable uncertainties to model evaluation. Third, though the HighResMIP GCMs has presented a better performance in simulating large-scale patterns of precipitation in Asia than other CMIP6 GCMs (Dong and Dong 2021), it still remains unknown whether HighResMIP can tackle the challenge of simulating regional-scale (less than $500-\mathrm{km}$ ) precipitation patterns.

In this paper, an assessment of the ability of atmosphere/ land-only (AMIP style) GCM simulations of HighResMIP, with a spectrum of both horizontal and vertical resolutions of the GCMs, to simulate the precipitation climatology and variability in Peninsular Malaysia will be performed. The assessment will provide model validations based on ensembles of multiple precipitation observations and climate reanalysis datasets, which helps to achieve more robust processes of model validation. The assessment aims to provide useful information on how to interpret the latest GCM simulation in Malaysia and the adjacent Western Maritime Continent for the further use of the models in hydrological impact studies. The specific objectives of this study are:

(a) To assess the realism of precipitation in different monsoon seasons over Peninsular Malaysia as simulated by the GCM simulations of HighResMIP.

(b) To investigate how the simulated precipitation in Peninsular Malaysia is affected by horizontal and vertical resolutions in those GCMs.

This paper is structured as follows. Section 2 briefly describes the study area, observational precipitation data and the HighResMIP experiments together with the methodology used for assessing the performance of the HighResMIP GCMs in simulating precipitation in Peninsular Malaysia. Section 3 presents the results of the assessment of the performance of the HighResMIP GCMs with different horizontal and vertical resolutions in simulating precipitation. Section 4 summarizes and discusses the main findings of the research.

\section{Data and methods}

\subsection{Observed precipitation data}

The study of Kotsuki and Tanaka (2013) suggested that considerable uncertainties exist in observed precipitation products over Southeast Asia. In this study, three different historical precipitation datasets are used for verifying the ability of the HighResMIP GCMs to simulate precipitation in Peninsular Malaysia. The use of multiple observational datasets helps to address the uncertainties in the observed precipitation and facilitates the evaluation of the model performance in simulating precipitation. The observed precipitation products used here include daily precipitation data from 53 rain gauge stations of the Malaysian Meteorological Department (MMD). The distribution of the 53 rain gauge stations is shown in Fig. 1. In addition, two gridded datasets of observed precipitation are used to validate the GCM simulations; Asian Precipitation- Highly-Resolved Observational Data Integration Towards Evaluation (APHRODITE, Yatagai et al. 2014) and Integrated Multi-satellitE Retrievals for Global Precipitation Measurement (IMERG-GPM referred to as GPM, Huffman et al. 2015). APHRODITE is a gridded daily precipitation dataset over land with a $25-\mathrm{km}$

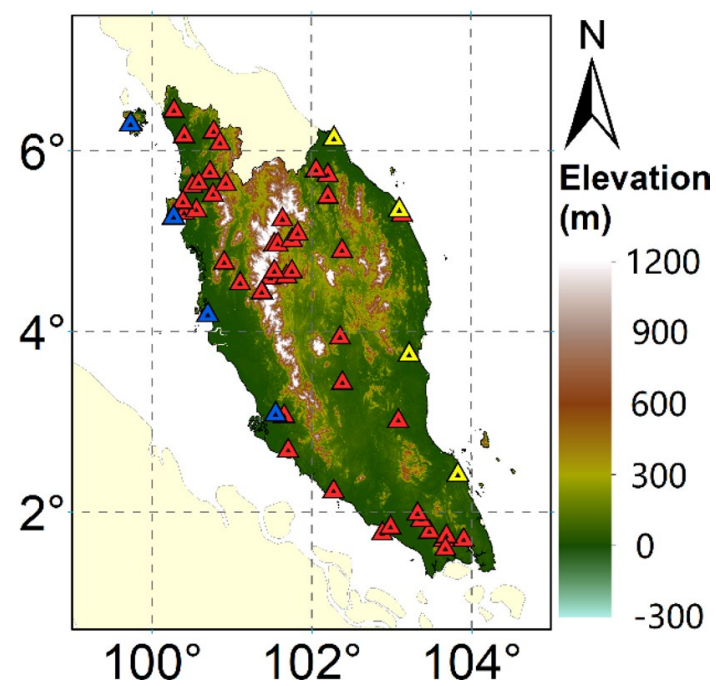

Fig. 1 Distributions of the 53 climate observing stations (triangles) and elevation [shaded, unit: $\mathrm{m}$; data from the 3 arc-seconds elevation data of the Shuttle Radar Topography Mission (Farr et al. 2007)] in Peninsular Malaysia. The four blue (yellow) triangles denote the stations for the west (east) coast of Peninsular Malaysia as per our analysis 
resolution developed by the Research Institute for Humanity and Nature and the Meteorological Research Institute of the Japan Meteorological Agency. This dataset was produced by interpolating in-situ rain gauge data using an angulardistance-weighting method to consider the local topography between rain gauge and interpolation point (Yatagai et al. 2014). APHRODITE has been used widely as verification data for studies of precipitation simulations over Southeast Asia (e.g. Ngai et al. 2017; Chung et al. 2018). GPM is a precipitation dataset based on satellites equipped with passive microwave sensors and active scanning radars, which is produced by NASA and the Japan Aerospace and Exploration Agency (Huffman et al. 2015). This dataset provides daily precipitation estimates with a spatial resolution of $0.1^{\circ} \times 0.1^{\circ}$ (approximately $11-\mathrm{km}$ latitude and longitude over Malaysia) available since June 2000 over the domain from $60^{\circ} \mathrm{N}$ to $60^{\circ} \mathrm{S}$.

\subsection{Reanalysis data}

Due to the strong association of precipitation patterns in Peninsular Malaysia with the onsets, peaks and transitions through different monsoon regimes (e.g. Chang et al. 2005; Tan et al. 2015; Chenoli et al. 2018), it is important to understand how well the GCMs can represent the monsoon circulation in different seasons, in addition to the associated precipitation. To evaluate the ability of the HighResMIP GCMs in simulating the large-scale environments associated with precipitation, four different reanalysis datasets are used as validation data to compare with the simulated large-scale fields from the HighResMIP GCMs. The use of multiple reanalysis datasets helps to reduce uncertainties associated with the different reanalysis models and different data assimilation methods (Bengtsson et al. 2004), such that the reliability of the model evaluation is improved. The precipitation-related environmental fields to be evaluated include the vertically integrated water vapor transport (IVT) and vertical velocity at $850 \mathrm{hPa}$ for the southwest monsoon (May to August, MJJA) and northeast monsoon (November to February, NDJF) seasons during the period 1979-2014. The reanalysis datasets used here are from the Fifth Generation ECMWF Atmospheric Reanalysis (ERA5), the Japanese 55-year Reanalysis (JRA-55), the Modern-Era Retrospective analysis for Research and Applications-version 2 (MERRA-2) and the National Centers for Environmental Prediction-Climate Forecast System Reanalysis (NCEPCFSR). The model resolution, data assimilation models and references of these datasets are summarized in Table 1.

\subsection{The HighResMIP experiments}

HighResMIP is an integral protocol of CMIP6 (Eyring et al. 2016). The protocol provides high-resolution GCM ensembles to allow for robust assessment of the impact of increased model resolution on "the simulated mean climate and its variability", so as to improve understanding of the "origins and consequences of systematic model biases" (Haarsma et al. 2016). As defined by HighResMIP, pairs of GCM simulations were run, with both atmosphere-only (AMIP) and coupled climate models over the historical (1950-2014) and future (2015-2050) periods, under the high-emission SSP585 scenario, (O'Neill et al. 2014).

In this study, the simulated precipitation and associated environmental variables from 20 historical simulations for the period 1979-2014 of the atmosphere-only experiments based on 11 GCMs are used. The initial atmospheric and land-surface conditions of these experiments are based on the ERA-20C reanalysis data (Poli et al. 2016). These experiments consider historical sea-ice and sea surface temperature forcing based on the HadISST2.2.0 data (Titchner and Rayner et al. 2014). Anthropogenic aerosol forcing including aerosol optical depth and changes in cloud effective radius deltas are based on the MACv2.0-SP model (Stevens et al. 2017). The forcing of volcanic activity, natural aerosol, greenhouse gases and solar radiation are the same as those used in the CMIP6 historical climate simulations described by Eyring et al. (2016).

To investigate the impact of model resolution on the simulation of precipitation and related environmental fields, the HighResMIP simulations are categorized into different groups for inter-comparison, including low horizontal resolution (Lh), high horizontal resolution $(\mathrm{Hh})$, low vertical resolution ( $\mathrm{Lv})$ and high vertical resolution $(\mathrm{Hv})$. The $\mathrm{Lh}(\mathrm{Hh})$ group includes simulations run at grid

Table 1 Summary of the reanalysis datasets used for model validation

\begin{tabular}{|c|c|c|c|c|}
\hline Organizations & Dataset name & $\begin{array}{l}\text { Horizontal resolution } \\
\text { (longitude } \times \text { latitude) }\end{array}$ & $\begin{array}{l}\text { Vertical } \\
\text { resolution } \\
\text { (No. of } \\
\text { levels) }\end{array}$ & References \\
\hline European Centre for Medium-Range Weather Forecasts & ERA5 & $0.25^{\circ} \times 0.25^{\circ}$ & 137 & Hersbach et al. (2020) \\
\hline The Japan Meteorological Agency & JRA-55 & $0.5^{\circ} \times 0.5^{\circ}$ & 60 & Kobayashi et al. (2015) \\
\hline The National Aeronautics and Space Administration, U.S & MERRA-2 & $0.5^{\circ} \times 0.625^{\circ}$ & 72 & Gelaro et al. (2017) \\
\hline National Centers for Environmental Prediction, U.S & NCEP-CFSR & $0.312^{\circ} \times 0.312^{\circ}$ & 91 & Saha et al. (2010) \\
\hline
\end{tabular}


spacings greater (less) than about $0.6^{\circ}(\sim 70-\mathrm{km})$. The $\mathrm{Lv}$ $(\mathrm{Hv})$ group includes the simulations of fewer (more) than 80 atmospheric vertical levels. Noted that the criterion of horizontal resolution acts to classify all the IPSLCM6A simulations as Lh and all the MRI-AGCM3-2 and NICAM16 simulations as Hh. With such a classification, the comparison between the ensemble of the Lh and Hh simulations will reflect more effects of the different GCM configurations (dynamical core, physical parameterizations etc.). To better generalize the effect of horizontal resolution, we classify the high-resolution version of IPSL-CM6A $\left(0.703^{\circ} \times 0.5^{\circ}\right)$ as $\mathrm{Hh}$ and the lowresolution versions of MRI-AGCM3-2 and NICAM16 $\left(0.563^{\circ} \times 0.563^{\circ}\right)$ as Lh. Approximately half of the experiments fall in $\mathrm{Hv}$ and half in $\mathrm{Hh}$. The combined effect of the horizontal and vertical resolution on the simulation will be investigated by the intercomparison among $\mathrm{Lh}-\mathrm{Lv}$, Lh-Hv, Hh-Lv and Hh-Hv, although their ensemble sizes are small (six models or less) and are difficult to fully exclude model uncertainty. Information on the selected HighResMIP experiments and the corresponding resolution groups is given in Tables 2 and 3 respectively.

\subsection{Methods for model validation}

The ability of the HighResMIP GCMs to simulate precipitation in Peninsular Malaysia is assessed by comparing with the different precipitation observation datasets, including MMD, APHRODITE and GPM. All the precipitation data from the different observation datasets and GCMs are interpolated to the 53 rain gauge stations of MMD shown in Fig. 1. The inter-comparison of precipitation among the different models and observational data are made at the rain gauge stations. The interpolation is performed based on the two-dimensional cubic spline method (Alfeld et al. 1984). The same method is used to replace the missing data in the MMD precipitation observation with the interpolated values based on the available data of the time step, though most of the applied MMD observations are from the principal climate stations of the WMO which are well maintained and thus contain fewer missing values than other stations (Tan et al. 2021). The inter-comparison of the full-year precipitation amount and those during the southwest monsoon (MJJA) and northeast monsoon (NDJF) seasons is made for the observed precipitation data and the GCM simulations.

Table 2 Summary of the used GCMs from the CMIP6 HighResMIP experiments

\begin{tabular}{|c|c|c|c|c|c|c|}
\hline Label No & Modeling organizations & Model name & $\begin{array}{l}\text { Horizontal resolution } \\
\text { (longitude } \times \text { latitude) }\end{array}$ & $\begin{array}{l}\text { Vertical } \\
\text { resolu- } \\
\text { tion } \\
\text { (No. of } \\
\text { levels) }\end{array}$ & Hori. res. categ & Vert. res. categ \\
\hline 1 & \multirow{3}{*}{$\begin{array}{l}\text { The UK Met Office Hadley Centre for Cli- } \\
\text { mate Change }\end{array}$} & \multirow[t]{3}{*}{ HadGEM3-GC31 } & $1.875^{\circ} \times 1.25^{\circ}$ & \multirow[t]{3}{*}{85} & Lh & $\mathrm{Hv}$ \\
\hline 2 & & & $0.83^{\circ} \times 0.56^{\circ}$ & & $\mathrm{Lh}$ & $\mathrm{Hv}$ \\
\hline 3 & & & $0.35^{\circ} \times 0.23^{\circ}$ & & $\mathrm{Hh}$ & $\mathrm{Hv}$ \\
\hline 4 & \multirow{2}{*}{$\begin{array}{l}\text { French National Centre for Meteorological } \\
\text { Research }\end{array}$} & \multirow[t]{2}{*}{ CNRM-CM6-1 } & $1.406^{\circ} \times 1.406^{\circ}$ & \multirow[t]{2}{*}{91} & Lh & $\mathrm{Hv}$ \\
\hline 5 & & & $0.5^{\circ} \times 0.5^{\circ}$ & & $\mathrm{Hh}$ & $\mathrm{Hv}$ \\
\hline 6 & \multirow{2}{*}{$\begin{array}{l}\text { European Centre for Medium-Range } \\
\text { Weather Forecasts }\end{array}$} & \multirow[t]{2}{*}{ ECMWF-IFS } & $1.0^{\circ} \times 1.0^{\circ}$ & \multirow[t]{2}{*}{91} & Lh & $\mathrm{Hv}$ \\
\hline 7 & & & $0.5^{\circ} \times 0.5^{\circ}$ & & $\mathrm{Hh}$ & $\mathrm{Hv}$ \\
\hline 8 & \multirow[t]{2}{*}{27 institutes in Europe (Haarsma et al. 2020) } & \multirow[t]{2}{*}{ EC-Earth3P } & $0.703^{\circ} \times 0.703^{\circ}$ & \multirow[t]{2}{*}{91} & Lh & $\mathrm{Hv}$ \\
\hline 9 & & & $0.352^{\circ} \times 0.352^{\circ}$ & & $\mathrm{Hh}$ & $\mathrm{Hv}$ \\
\hline 10 & \multirow[t]{2}{*}{ Meteorological Research Institute (Japan) } & \multirow[t]{2}{*}{ MRI-AGCM3-2 } & $0.563^{\circ} \times 0.563^{\circ}$ & \multirow[t]{2}{*}{60} & Lh & $\mathrm{Lv}$ \\
\hline 11 & & & $0.188^{\circ} \times 0.188^{\circ}$ & & $\mathrm{Hh}$ & $\mathrm{Lv}$ \\
\hline 12 & \multirow{2}{*}{$\begin{array}{l}\text { Japan Agency for Marine-Earth Science and } \\
\text { Technology }\end{array}$} & \multirow[t]{2}{*}{ NICAM16 } & $0.563^{\circ} \times 0.563^{\circ}$ & \multirow[t]{2}{*}{38} & $\mathrm{Lh}$ & $\mathrm{Lv}$ \\
\hline 13 & & & $0.281^{\circ} \times 0.281^{\circ}$ & & $\mathrm{Hh}$ & $\mathrm{Lv}$ \\
\hline 14 & \multirow{2}{*}{$\begin{array}{l}\text { Institute of Atmospheric Physics/ Chinese } \\
\text { Academy of Sciences }\end{array}$} & \multirow[t]{2}{*}{ FGOALS-f3 } & $1.25^{\circ} \times 1^{\circ}$ & \multirow[t]{2}{*}{32} & Lh & $\mathrm{Lv}$ \\
\hline 15 & & & $0.25^{\circ} \times 0.25^{\circ}$ & & $\mathrm{Hh}$ & $\mathrm{Lv}$ \\
\hline 16 & $\begin{array}{l}\text { Geophysical Fluid Dynamics Laboratory/ } \\
\text { NOAA (U.S.) }\end{array}$ & GFDL-CM4C192 & $0.625^{\circ} \times 0.5^{\circ}$ & 33 & Lh & $\mathrm{Lv}$ \\
\hline 17 & \multirow[t]{2}{*}{ Institude Pierre Simon Laplace (France) } & \multirow[t]{2}{*}{ IPSL-CM6A } & $2.5^{\circ} \times 1.259^{\circ}$ & \multirow[t]{2}{*}{79} & $\mathrm{Lh}$ & $\mathrm{Lv}$ \\
\hline 18 & & & $0.703^{\circ} \times 0.5^{\circ}$ & & $\mathrm{Hh}$ & $\mathrm{Lv}$ \\
\hline 19 & $\begin{array}{l}\text { Institute of Numerical Mathematics of the } \\
\text { Russian Academy of Sciences }\end{array}$ & INM-CM5-H & $0.67^{\circ} \times 0.5^{\circ}$ & 73 & $\mathrm{Lh}$ & $\mathrm{Lv}$ \\
\hline 20 & $\begin{array}{l}\text { Chinese Academy of Meteorological Sci- } \\
\text { ences }\end{array}$ & CAMS-CSM1 & $0.469^{\circ} \times 0.469^{\circ}$ & 31 & $\mathrm{Hh}$ & $\mathrm{Lv}$ \\
\hline
\end{tabular}


Table 3 Summary of the different resolution categories

\begin{tabular}{|c|c|c|c|c|}
\hline Resolution category & Label & $\begin{array}{l}\text { Number of experi- } \\
\text { ments }\end{array}$ & $\begin{array}{l}\text { Mean horizontal resolution } \\
\text { (longitude } \times \text { latitude) }\end{array}$ & $\begin{array}{l}\text { Mean vertical } \\
\text { resolution (No. of } \\
\text { levels) }\end{array}$ \\
\hline Low horizontal res & $\mathrm{Lh}$ & 11 & $1.089^{\circ} \times 0.846^{\circ}$ & 69 \\
\hline High horizontal res & $\mathrm{Hh}$ & 9 & $0.399^{\circ} \times 0.363^{\circ}$ & 66 \\
\hline Low vertical res & $\mathrm{Lv}$ & 11 & $0.732^{\circ} \times 0.552^{\circ}$ & 50 \\
\hline High vertical res & $\mathrm{Hv}$ & 9 & $0.835^{\circ} \times 0.722^{\circ}$ & 89 \\
\hline Low horizontal res. with low vertical res & $\mathrm{Lh}-\mathrm{Lv}$ & 6 & $1.028^{\circ} \times 0.731^{\circ}$ & 53 \\
\hline Low horizontal res. with high vertical res & $\mathrm{Lh}-\mathrm{Hv}$ & 5 & $1.163^{\circ} \times 0.984^{\circ}$ & 89 \\
\hline High horizontal res. with low vertical res & $\mathrm{Hh}-\mathrm{Lv}$ & 5 & $0.378^{\circ} \times 0.338^{\circ}$ & 48 \\
\hline High horizontal res. with high vertical res & $\mathrm{Hh}-\mathrm{Hv}$ & 4 & $0.426^{\circ} \times 0.396^{\circ}$ & 90 \\
\hline
\end{tabular}

The comparison focuses on the period 2001-2014 due to the limited data period of GPM.

The simulated distributions of precipitation-related variables from the HighResMIP models are evaluated, including the total precipitation amount during different seasons and the extreme precipitation (the 95th percentile of daily precipitation) rate for wet days (daily precipitation $>0.1 \mathrm{~mm}$ ) during NDJF. To investigate the capability of the models to simulate the relationship between precipitation and monsoon intensity, the Pearson correlation coefficients between the seasonal total precipitation and seasonal mean monsoon indices are analyzed. Due to the close relationship between the winter monsoonal flow over the South China Sea and the regional climate in the Maritime Continent (Zhang et al. 2019), the intensity of the northeast monsoon is computed by a Northeast Monsoon Index (NEMI) defined as the regional mean northeasterly wind speed at $850-\mathrm{hPa}$ over the main South China Sea $\left(5^{\circ} \mathrm{N}-20^{\circ} \mathrm{N}\right.$, $110^{\circ} \mathrm{E}-120^{\circ} \mathrm{E}$ ), following the study of Wang et al. (2009). For the southwest monsoon season (MJJA), a modified version of the Malaysian Meteorological Department Wind Shear Index (WSI) (Chenoli et al. 2018) is used to diagnose the monsoon intensity. The WSI is defined as the regional mean zonal wind component at 850 -hPa over the region of $1.75^{\circ} \mathrm{N}-4.25^{\circ} \mathrm{N}, 100.75^{\circ} \mathrm{E}-113.25^{\circ} \mathrm{E}$ minus that over $5^{\circ} \mathrm{N}-15^{\circ} \mathrm{N}, 90^{\circ} \mathrm{E}-130^{\circ} \mathrm{E}$.

We employ a variety of statistical techniques to evaluate the performance of each model with respect to the observed precipitation data. The Pearson correlation coefficient is used to quantify the similarity of the spatial distribution of a given variable between the GCM simulation and the observations. The root-mean-square error (RMSE) and the relative bias $(\mathrm{RB})$ are used to indicate the departure between the simulations and observations. These statistical measures are commonly used in precipitation studies over Malaysia (e.g. Tan et al. 2015; Xiang Soo et al. 2020). The Taylor diagram metric (Taylor 2001) is used to synthesize the variables (including correlation coefficient, centered root-mean-square difference (RMSD) and standard deviation) assessing the similarities of mean and variation between the simulations and observations.

\section{Results}

\subsection{Annual cycle of precipitation}

The annual cycles of precipitation in the three precipitation observation datasets and the different subsets of the HighResMIP GCM simulations separated into all-measurements, east-coast, and west-coast observations are shown in Fig. 2. The observed precipitation, from MMD, APHRODITE and GPM, at all the rain-gauge stations show two peaks of precipitation during March-April and November-December respectively (Fig. 2a). For selected stations along the west coast (Fig. 2b), two precipitation peaks are seen in April and October, implying a significant influence of the Inter-Tropical Convergence Zone (ITCZ) during the inter-monsoon seasons (Camerlengo et al. 1998). For the east coast, one precipitation peak is found in December due to the influence of the Northeast monsoon (Fig. 2c) and such an influence was highlighted by the extreme flood event induced by the longlasting precipitation across the east coast in December 2014 (Hai et al. 2017). The double-peak monthly distribution of the observed precipitation is represented reasonably well by all the GCMs (Fig. 2a). However, it is overestimated in the $\mathrm{Lh}$ and Lv simulations during the inter-monsoon seasons (April-May), by about $100 \%$ relative to the observational mean, (Obs. Mean) and October-November (by about onethird). Similar biases are found in the Hh-Lv simulations. In contrast, the simulations with relatively high vertical resolutions, including the $\mathrm{Hv}, \mathrm{Lh}-\mathrm{Hv}$ and $\mathrm{Hh}-\mathrm{Hv}$ simulations, have a better representation of the annual cycle of precipitation. Simulations with relatively high horizontal resolutions, including $\mathrm{Hh}, \mathrm{Hh}-\mathrm{Lv}$ and $\mathrm{Hh}-\mathrm{Hv}$, also tend to overestimate precipitation less than $\mathrm{Lh}, \mathrm{Lh}-\mathrm{Hv}$ and $\mathrm{Lh}-\mathrm{Hv}$ respectively. 

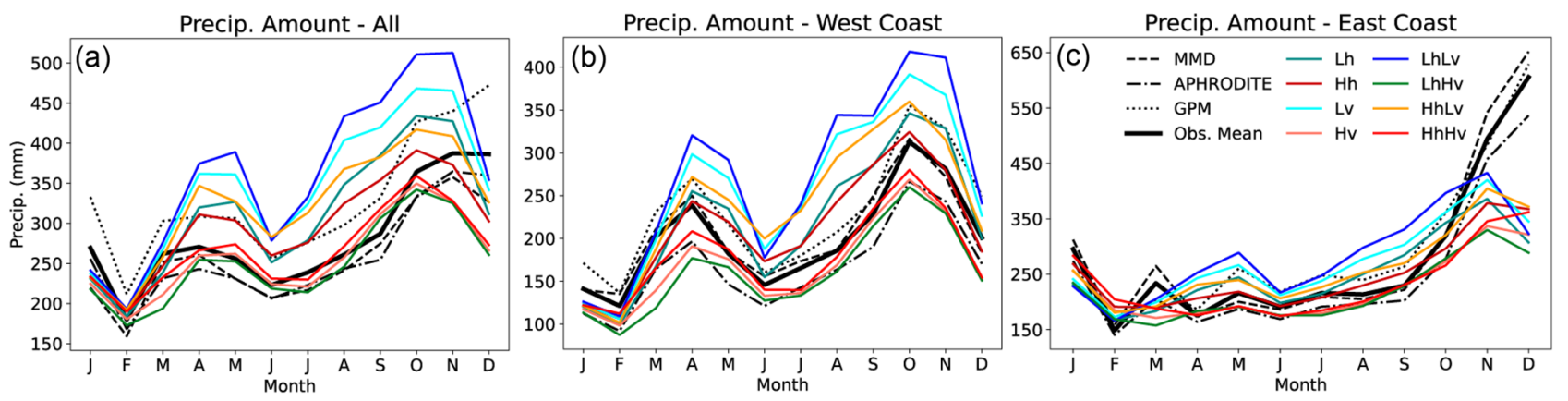

Fig. 2 Annual cycle of the regionally averaged precipitation amount for all the rain-gauge stations (a) and the stations along the west coast (b) and east coast (c) of Peninsular Malaysia

All the models simulate an earlier occurrence (by about a month) of the precipitation peak in October-December. For the west coast (Fig. 2b), all the simulations represent the observed precipitation peaks in April and October reasonably well, though the simulations with coarser vertical resolutions (Lv, Lh-Lv and Hh-Lv groups) tend to overestimate the precipitation by approximately one third. For the east coast (Fig. 2c), all the simulations underestimate the precipitation by at least $50 \%$ during November-December. Simulations with coarser horizontal resolutions (Lh, Lh-Lv and Lh-Hv) exhibit an earlier precipitation peak in November compared to that in December as shown by the observations. Similar biases have been noted over eastern Peninsular Malaysia in the RCM simulations for the dynamical downscaling domain of the Coordinated Regional Climate Downscaling Experiment-Southeast Asia (CORDEX-SEAsia, Tangang et al. 2020). A more reasonably simulated peak of precipitation in December is seen in simulations with finer horizontal resolutions ( $\mathrm{Hh}, \mathrm{Hh}-\mathrm{Lv}$ and $\mathrm{Hh}-\mathrm{Hv}$ ).

\subsection{Spatial distributions of precipitation}

Figure 3 shows the spatial distribution of the observed and simulated annual total precipitation for the period 2001-2014. Observed precipitation patterns show some significant differences. For the observed precipitation from MMD (Fig. 3a), APHRODITE (Fig. 3b) and GPM (Fig. 3c), the northeast and west coasts of Peninsular Malaysia have the highest precipitation totals, with annual precipitation greater than about $3000 \mathrm{~mm} /$ year on average across all the observed precipitation data (Fig. 3d). The MMD data indicates the north of the region is also affected by high precipitation totals ( $>2600 \mathrm{~mm} /$ year), though such estimated precipitation maxima are not seen in the APHRODITE and GPM data. Although the locations of precipitation maxima are similar in all observed precipitation datasets, the precipitation amount from APHRODITE is about $600 \mathrm{~mm} /$ year less than those in MMD and GPM, a similar result to previous studies (e.g. Tan et al. 2015;
Luo et al. 2020; Ji et al. 2020). However, each of the three precipitation data sets has its strengths and weaknesses. For instance, MMD provide high-quality observations, while the extreme variation in orography in Peninsular Malaysian can lead to spatially inhomogeneous samples (Stokstad 1999). The gridded APHRODITE and GPM datasets provide more uniformly distributed data, while the production of these data is affected by the uncertainties in interpolation methods (Herrera et al. 2018) and satellite observation errors (Tian et al. 2010; Maggioni et al. 2016). Considering the uncertainties in observations varying as a function of location and season, the following section assesses the performance of GCMs against each of the precipitation datasets.

In the Lh simulations (Fig. 3e), a precipitation maximum is found in the mid-north of the region. The pattern of precipitation is poorly simulated as indicated by the negative correlation coefficient relative to all the observation datasets. For Hh (Fig. 3f), a higher correlation with the observations is found. However, the Hh subset still fails to capture the observed precipitation maximum along the northeast coast. For Lv (Fig. 3g), the models show a general overestimation of precipitation with positive relative bias (RB) compared to the observations. In contrast, the Hv simulations (Fig. 3h) show less precipitation across the region. A higher correlation with the observations is also seen in Hv compared to Lv. The Lh-Lv and Hh-Lv simulations show relatively low correlations $(<0.3)$ with the observations. In comparison, the Lh-Hv simulations show a higher correlation, indicating an improved simulation of the observed distribution when a higher horizontal or vertical resolution is used. The $\mathrm{Hh}-\mathrm{Hv}$ group presents the best-simulated distribution with the highest correlation with the observations and least RMSE. $\mathrm{Hh}-\mathrm{Hv}$ simulations also correctly simulate the observed precipitation maximum over the northeast coast of the region, though underestimation is found (negative RB) compared to all the observations. It is also noticeable that the RMSE, RB and correlation coefficient for all the simulations vary with the compared observation data, implying that uncertainty 
(a) MMD

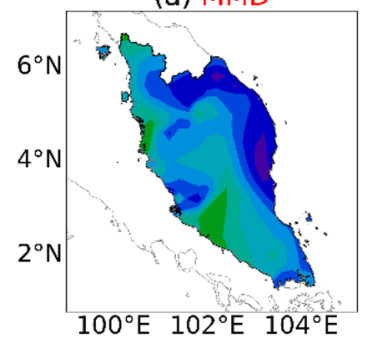

(e) Lh

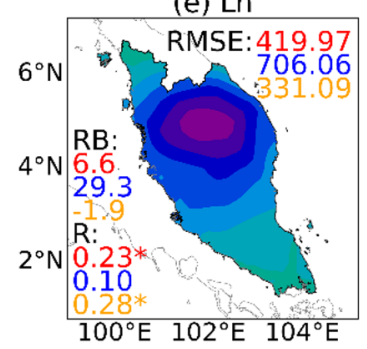

(i) Lh-LV

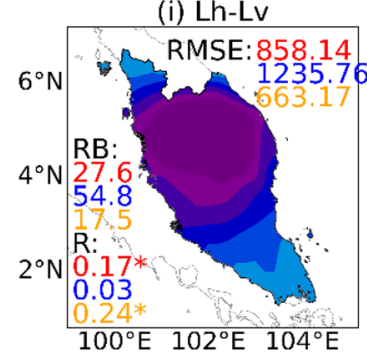

(b) APHRODITE

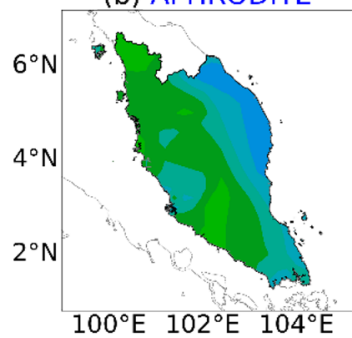

(f) $\mathrm{Hh}$

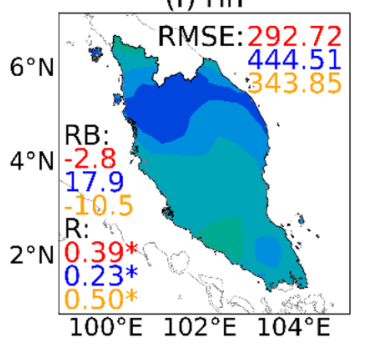

(j) Lh-Hv

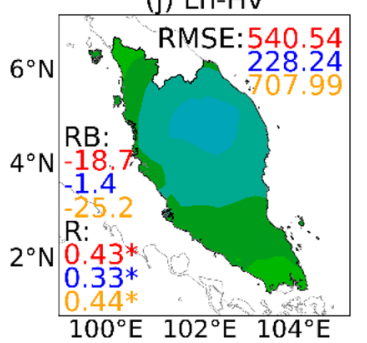

(c) GPM

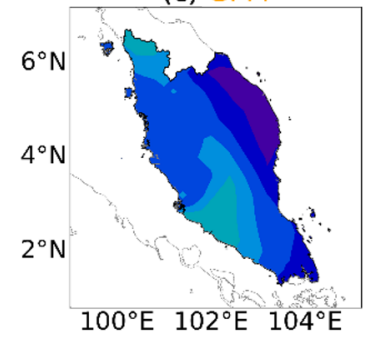

(g) LV

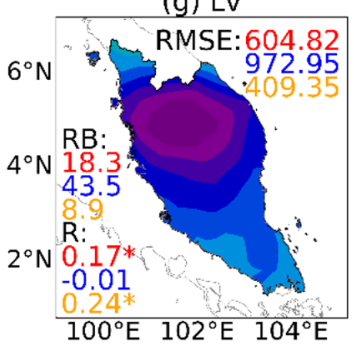

(k) Hh-Lv

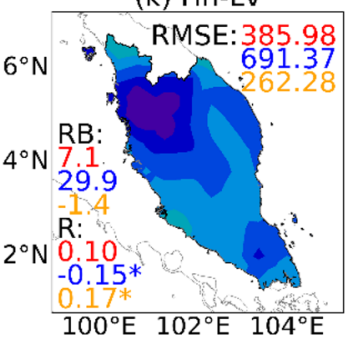

(d) Obs. Mean

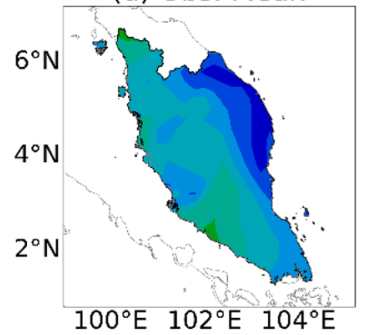

(h) $\mathrm{Hv}$

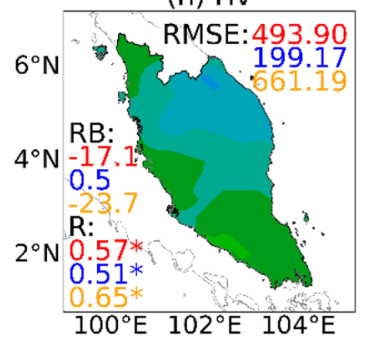

(I) $\mathrm{Hh}-\mathrm{Hv}$

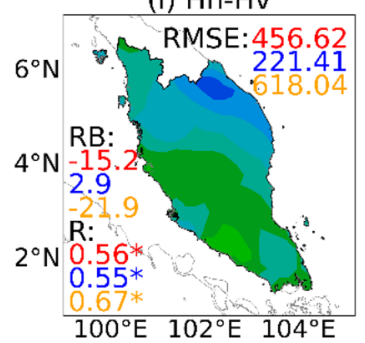

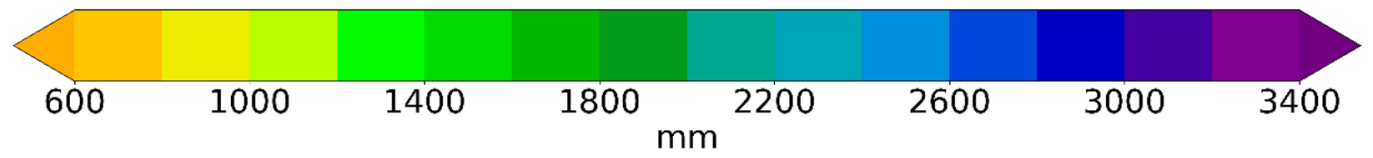

Fig. 3 Spatial distribution of the annual precipitation amount for the period 2001-2014. The root-mean-square error (RMSE), relative bias (RB) and correlation coefficient (R) between each simulation group and the observed precipitation are shown in red (relative to MMD),

in observed precipitation datasets limits their capacity for model evaluation at higher temporal and spatial scales.

The rainfall characteristics in Peninsular Malaysia exhibit strong seasonal variation due to the influence of the Northeast and Southwest monsoons (Varikoden et al. 2011; Tan 2018). Here, the analysis of the seasonal changes in precipitation for the wet Northeast monsoon season (NDJF) with respect to the dry Southwest monsoon season (MJJA) is shown in Fig. 4. For the observed precipitation over the region (Fig. 4a-d), a significant increase in precipitation is seen during the Northeast monsoon season, especially over the northeast coast (by up to $800 \mathrm{~mm} / \mathrm{season}$ ) and the southwest (by up to $400-600 \mathrm{~mm} / \mathrm{season}$ ). Decreased precipitation during the Northeast monsoon season (by up to about $100-300 \mathrm{~mm} / \mathrm{season}$ ) is shown in the northwest, though APHRODITE and GPM do not suggest these changes are statistically significant. The Lh (Fig. 4e) and Lh-Lv (Fig. 4i) blue (APHRODITE) and orange (GPM). Asterisk indicates the correlation at a confidence level above $90 \%$ (two-tailed $p$-value $<0.1$ ) based on Student's t-test

simulations show a significant precipitation decrease across the north of the region and fail to capture the observed precipitation increase in the northeast coast and the southwest. Simulations with higher horizontal resolutions, including $\mathrm{Hh}$ (Fig. 4f), Hh-Lv (Fig. 4k) and Hh-Hh (Fig. 4l) show a better simulation of the precipitation increase along the northeast coast than those with lower horizontal resolution. However, the amplitude of the annual cycle of precipitation is still underestimated over most of the region, which is consistent with the underestimated precipitation in December and the overestimation during MJJA (Fig. 3). Compared with Lv (Fig. 4g), Lh-Lv (Fig. 4i) and Hh-Lv (Fig. 4k), simulations with finer vertical resolutions, including Hv (Fig. 4h), Lh-Hv (Fig. 4j) and Hh-Hv (Fig. 4l), show an improved simulation with higher correlation and lower RMSE and RB in general. The Hh-Hv simulations exhibit the lowest RMSE and RB against every observational dataset compared to the 


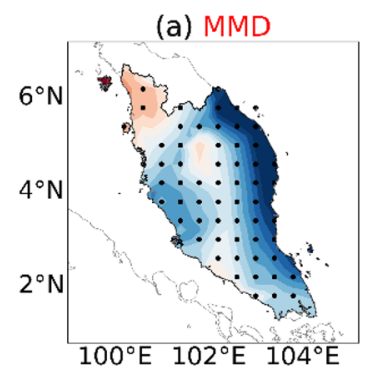

(e) Lh

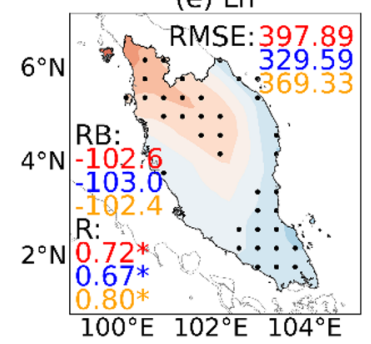

(i) Lh-Lv

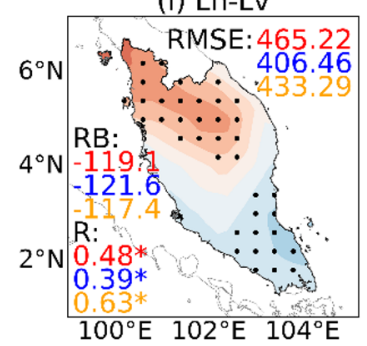

(b) APHRODITE

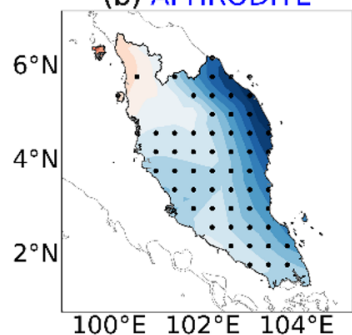

(f) $\mathrm{Hh}$

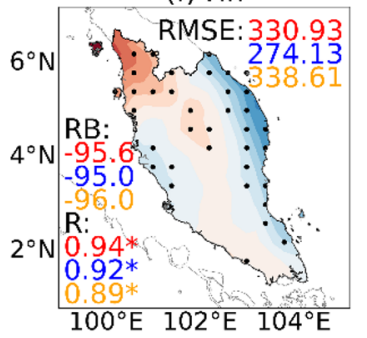

(j) Lh-Hv

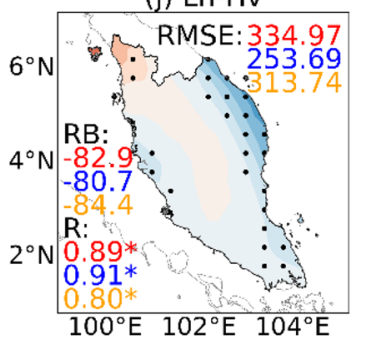

(c) GPM

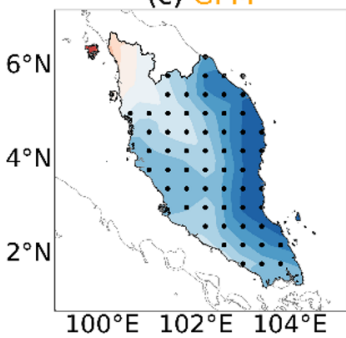

(g) LV

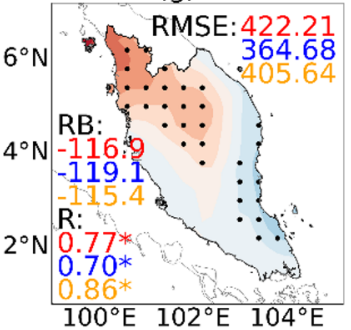

(k) Hh-LV

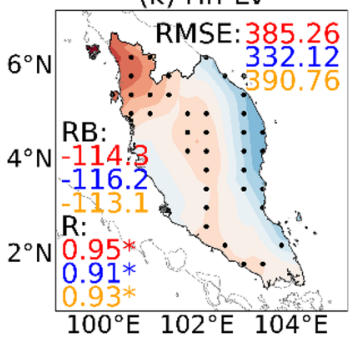

(d) Obs. Mean

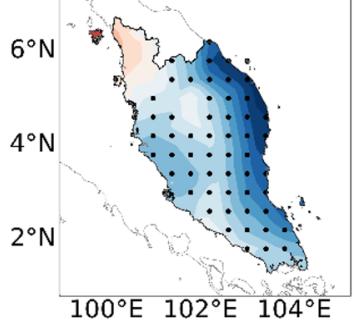

(h) $\mathrm{Hv}$

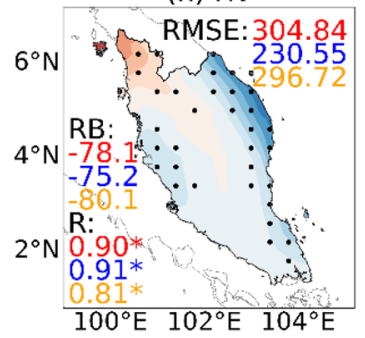

(I) $\mathrm{Hh}-\mathrm{Hv}$

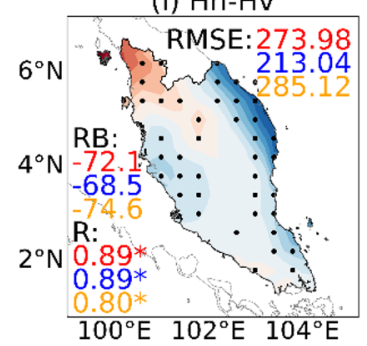

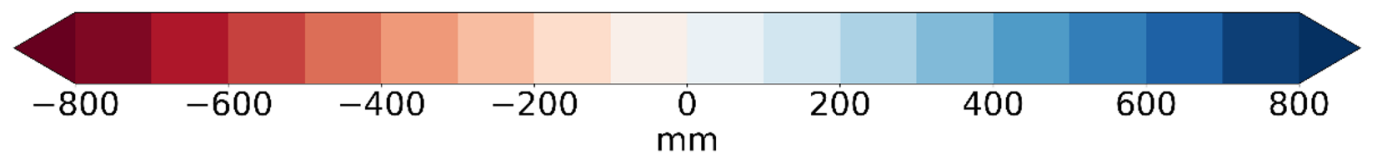

Fig. 4 Same as Fig. 3, but for the difference of total precipitation between the Northeast monsoon season (November to February, NDJF) and the Southwest monsoon season (May to August, MJJA).

other groups. They also exhibit the best representation of the observed precipitation increase over both the northeast coast and the southwest during the Northeast monsoon season, though the spatial correlation with the observations is not improved.

The Taylor diagrams in Fig. 5 provide a statistical comparison between the simulated precipitation distributions with different resolutions and the mean precipitation from the four different observational datasets. Black dots indicate that the different observed precipitation datasets exhibit some consistencies in the spatial pattern of precipitation in different seasons, though APHRODITE and GPM show a lower standard deviation compared to MMD. The Hh-Hv simulations perform the best in simulating the precipitation distribution during the Northeast monsoon (NDJF) seasons in terms of RMSD. For the Southwest monsoon seasons (MJJA), the Lh-Hv simulations show the lowest RMSD, while Hh-Hv shows the highest correlation
Black stippling indicates the statistically significant difference at the 95\% confidence level via the Student's t-test

with the observed precipitation compared to other groups. Additionally, for the total precipitation during the fullyear and the MJJA periods, the Lh-Hv simulations outperform $\mathrm{Hh}-\mathrm{Lv}$ and $\mathrm{Lh}-\mathrm{Lv}$, implying the importance of using fine vertical resolutions for a realistic simulation of precipitation. Comparing the NDJF period with MJJA, a larger spread is seen and it implies a greater model uncertainty in the simulation of the Northeast monsoon seasons. Moreover, for the different periods, the simulations at relatively high vertical resolution ( $\mathrm{Lh}-\mathrm{Hv}$ and $\mathrm{Hh}-\mathrm{Hv}$ ) generally show smaller spreads of scattering compared to the coarse vertical resolution simulations ( $\mathrm{Lh}-\mathrm{Lv}$ and $\mathrm{Hh}-\mathrm{Hv}$ ). Also, for Lh-Hv, Hh-Lv and Hh-Hv, the correlations with observations are higher in NDJF than those in MJJA. Similar results have been found when the simulated precipitation over Southeast Asia during DJF is compared with that in JJA using the RCM simulations of the CORDEX-SEAsia experiments (Tangang et al. 2020). 


\section{(a) Full-Year}

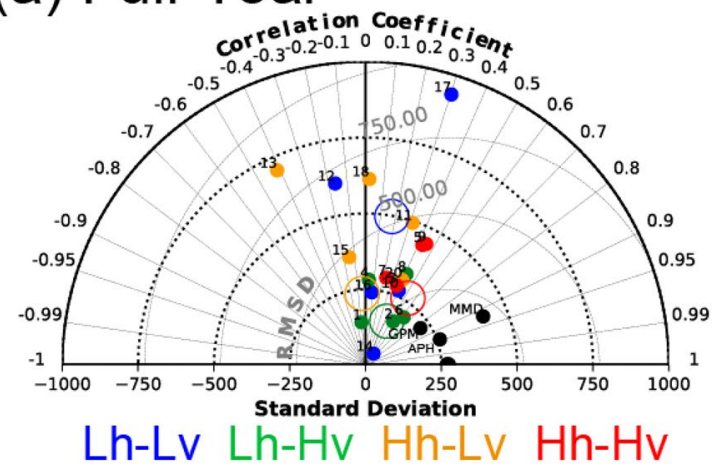

(b) NDJF

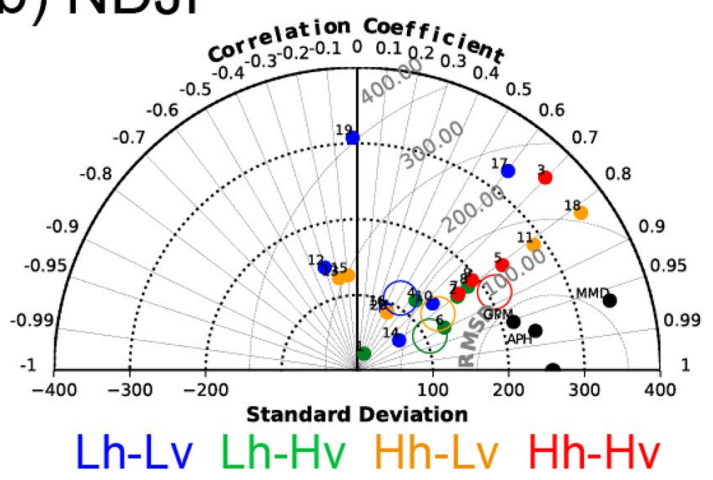

Fig. 5 Taylor diagrams for the spatial comparisons of the precipitation amount during the full-year (a), northwest (b) and southwest monsoon (c) seasons between the ensemble mean of observed precipitation and each simulation for the different resolution groups. Black dots show the statistics for the different observed precipitation data-

In summary, models with finer horizontal and vertical resolutions exhibit a better representation of precipitation distribution. Such an improvement is more prominently shown during the Northeast monsoon season. However, simulation for the Southwest monsoon seasons is not significantly improved. This limits the improvement in simulating the spatial shift of precipitation between the different monsoon seasons.

\subsection{Relationship between monsoon intensity and precipitation}

The simulated relationship between monsoon intensity and precipitation over Peninsular Malaysia, in terms of Pearson correlation coefficients between seasonal total precipitation and seasonal mean NEMI and WSI, is shown in Figs. 6 and 7. For the northeast monsoon season, the observed precipitation from MMD (Fig. 6a), APHRODITE (Fig. 6b), GPM (Fig. 6c) and their ensemble mean (Fig. 6d) suggest positive correlations $(>0.5)$ with NEMI on the windward side of the Titiwangsa Mountains (near $4.6^{\circ} \mathrm{N}, 101.4^{\circ} \mathrm{E}$ ) and the East (c) MJJA

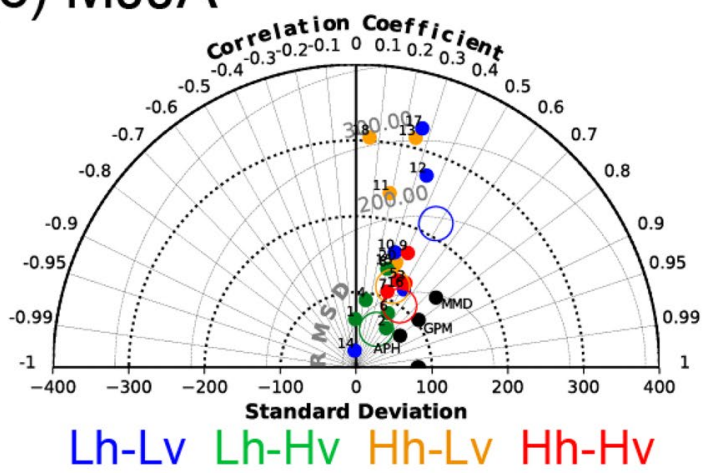

sets, including MMD, APHRODITE (APH) and GPM. Rings show the statistics for the ensemble mean of simulations for the different resolution groups. The labelled number of scatters for each simulation is the same as that listed in Table 2

Coast Range (near $4.8^{\circ} \mathrm{N}, 102.8^{\circ} \mathrm{E}$ ), implying an increase (decrease) in precipitation amount due to a stronger (weaker) winter monsoon. Uncertainty in the observed precipitation datasets means the location of significant correlations varies from the center to the southeast of the region. The Lh (Fig. 6e) simulations show correlation coefficients between 0.15 and 0.3 over the region and are underestimated by up to about 0.4 over the center to the east coast compared to the observational mean. The Hh simulations exhibit a higher correlation coefficient compared to Lh and the location of the observed correlation maximum across the east is captured reasonably well, while underestimation still exists. An obvious underestimation of correlation is also noted in the Lv simulations. With increased vertical resolutions, the $\mathrm{Hv}$ ensemble mean shows higher correlation coefficients compared to Lv; however, the simulations fail to capture the location of maximum correlation over the east. As shown in Fig. 6i and $\mathrm{j}$, the $\mathrm{Lh}-\mathrm{Lv}$ and $\mathrm{Lh}-\mathrm{Hv}$ simulations poorly capture the correlation pattern. Comparison of Fig. 6i-1 shows that the ensemble of $\mathrm{Hh}-\mathrm{Hv}$ simulations has the least RMSE and RB when compared with every observational data set 


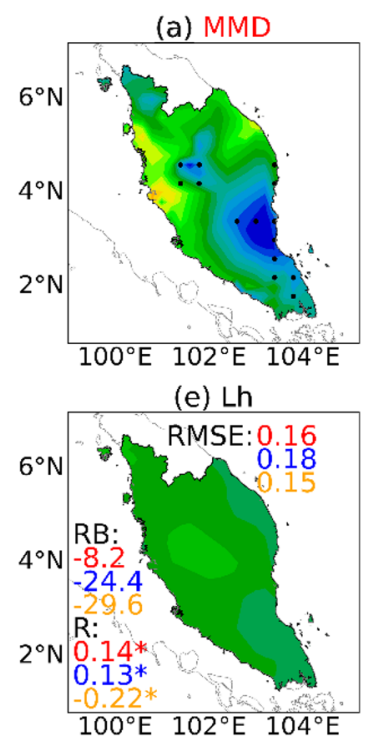

(i) Lh-Lv

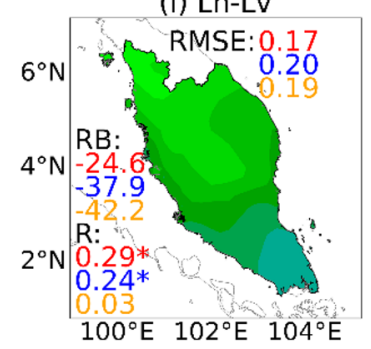

(b) APHRODITE

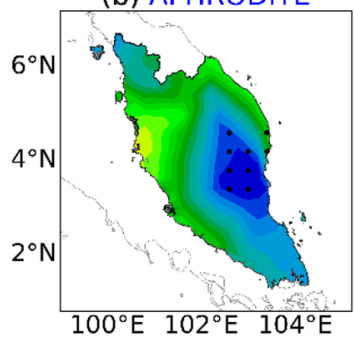

(f) $\mathrm{Hh}$

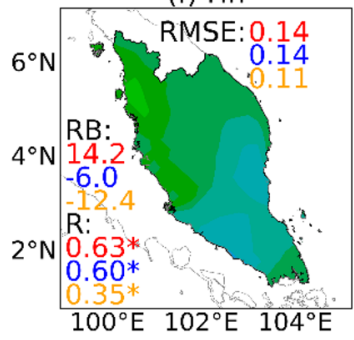

(j) Lh-Hv

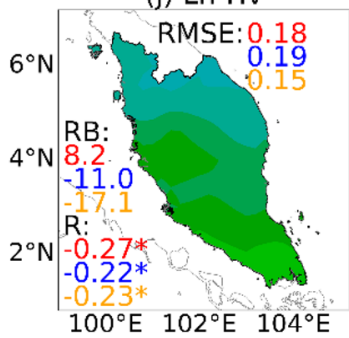

(c) GPM

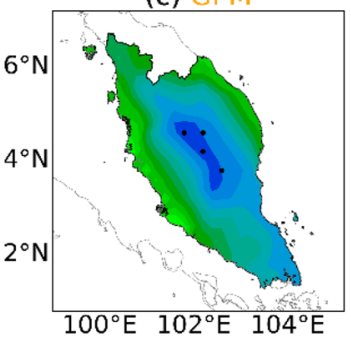

(g) LV

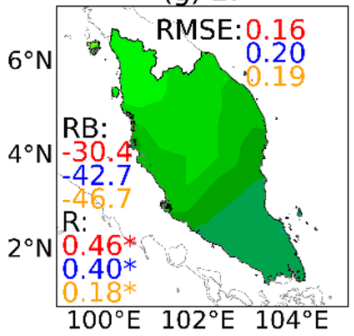

(k) Hh-Lv

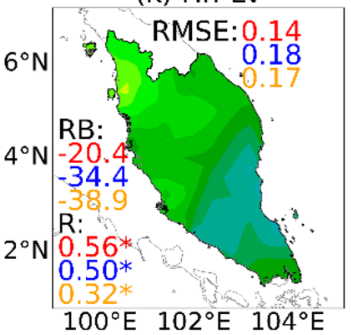

(d) Obs. Mean

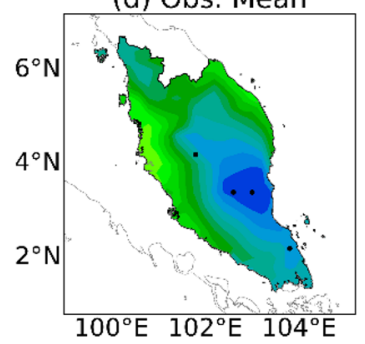

(h) $\mathrm{HV}$

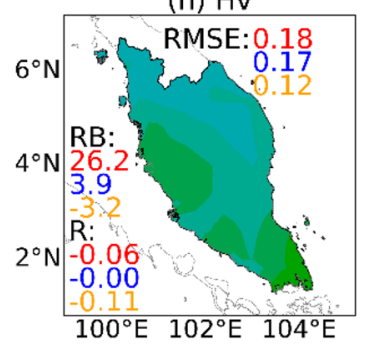

(I) $\mathrm{Hh}-\mathrm{HV}$

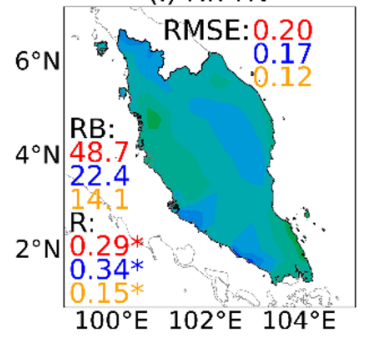

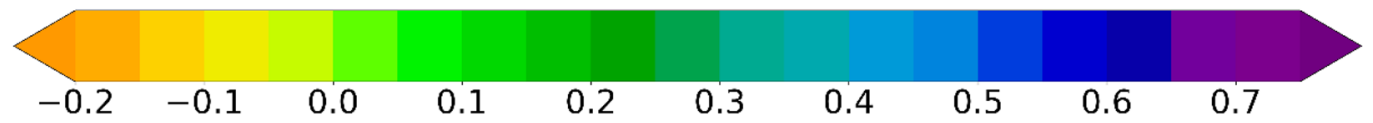

Fig. 6 Pearson correlation coefficients between NDJF-mean NEMI and the total precipitation during NDJF. Black stippling indicates the statistically significant correlation at the $95 \%$ confidence level (two-tailed $p$-value $<0.05$ )

compared to the other groups. The simulated correlation coefficients are up to 0.5 over the east, which is higher than other simulations and mostly similar to the observational mean. However, overestimations are seen over the north and southwest of the region. The Hh-Lv simulations show the most similar spatial pattern to the observational mean (in terms of correlation coefficient with the observed precipitation), though more underestimation is seen compared to $\mathrm{Hh}-\mathrm{Hv}$. It is also noted that all simulation groups show no statistically significant correlation in contrast to the observations.

During the southwest monsoon season, all the observed precipitation datasets (Fig. 7a-d) suggest relatively high correlation coefficients between precipitation and WSI across the southwest windward side of the region. The MMD shows the highest maximum of correlation coefficient by up to 0.75 . The correlation presented by GPM is generally weaker than other observational datasets. Comparison of Fig. 7e-h shows that increases in model resolution can result in higher monsoon-precipitation correlation over the southwest, especially for the increase in vertical resolution (by up to 0.3 , Fig. $7 \mathrm{~g}$ and $\mathrm{h}$ ). In contrast to $\mathrm{Lh}, \mathrm{Hh}$ and $\mathrm{Lv}$, the $\mathrm{Hv}$ simulations successfully represent the statistically significant correlation across the southwest in the observations. Comparison of Fig. 7i-1 suggests that the $\mathrm{Lh}-\mathrm{Hv}$ group has the most similar spatial pattern to the observational mean (in terms of R) compared to $\mathrm{Lh}-\mathrm{Lv}$, Hh-Lv and $\mathrm{Hh}-\mathrm{Hv}$, while $\mathrm{Hh}-\mathrm{Hv}$ generally shows the lowest RMSE and RB with respect to the observational datasets.

Overall, the GCM simulations with coarser horizontal and vertical resolutions tend to produce a weaker relationship between precipitation and monsoon intensity during the different monsoon seasons. Improved simulations of such relationships can be obtained by the use of sufficiently high horizontal and vertical resolutions and such an improvement is more obviously seen during the southwest monsoon seasons. 
(a) MMD

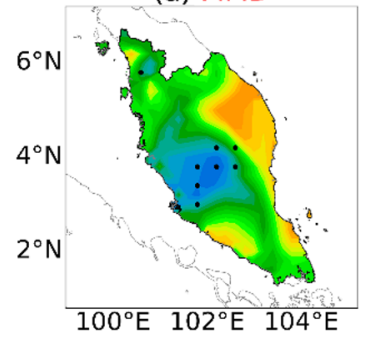

(e) Lh

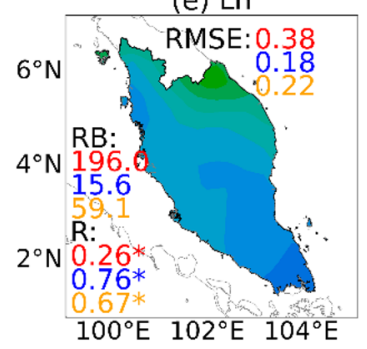

(i) Lh-LV

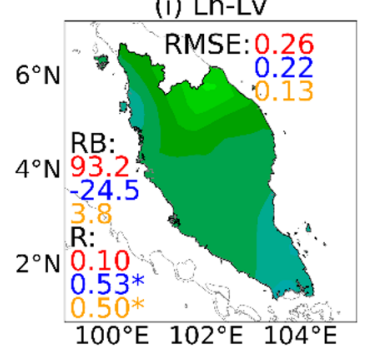

(b) APHRODITE

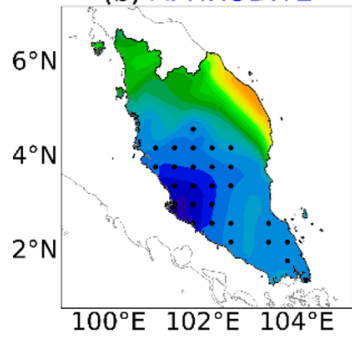

(f) $\mathrm{Hh}$

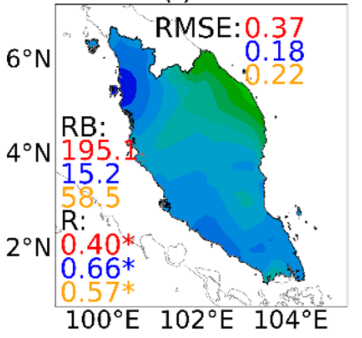

(j) Lh-HV

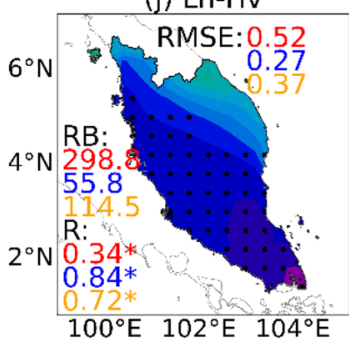

(c)

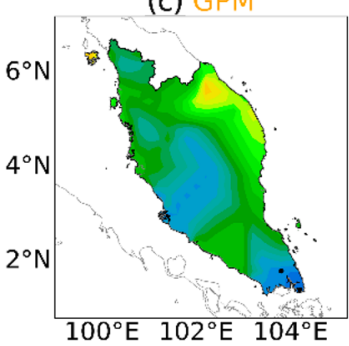

(g) LV

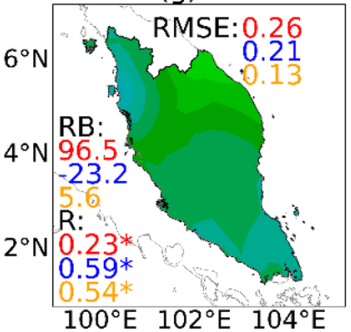

(k) Hh-LV

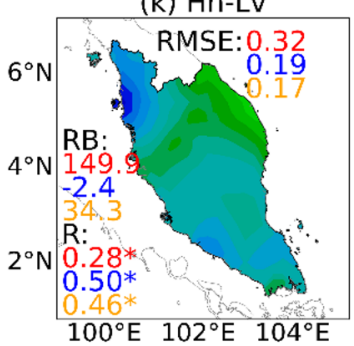

(d) Obs. Mean

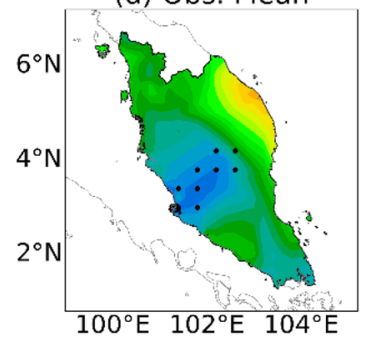

(h) $\mathrm{HV}$

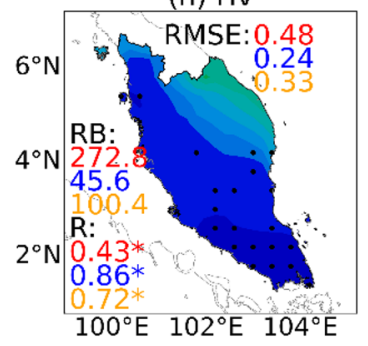

(I) $\mathrm{Hh}-\mathrm{Hv}$

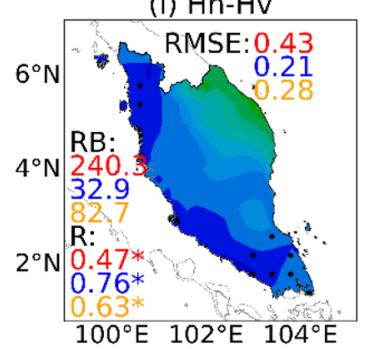

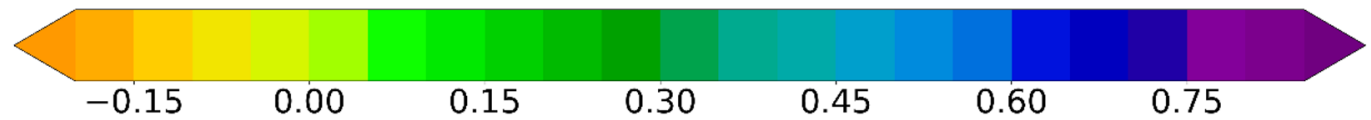

Fig. 7 As Fig. 6, but for correlation coefficients between MJJA-mean WSI and the total precipitation during MJJA

\subsection{Extreme precipitation}

Extreme precipitation during the Northeast monsoon season is closely associated with severe flooding over Peninsular Malaysia (e.g. Tangang et al. 2008; Hai et al. 2017) and the reliable projections of changes in these extremes are therefore key to understanding the likely impact of climate change in the region. To evaluate the ability of the HighResMIP models to simulate the extreme precipitation in the region, the distribution of the 95th percentile maximum daily precipitation during the Northeast monsoon season (NDJF) from the different observed precipitation data and the ensemble mean of each resolution group are presented (Fig. 8). The MMD (Fig. 8a), APHRODITE (Fig. 8b) and GPM (Fig. 8c) show the regions with the highest extreme precipitation rates ( $>76 \mathrm{~mm} /$ day in NDJF) occur along the northeast coast of Peninsular Malaysia. In these regions, MMD and GPM show a higher precipitation rate (approximately double) compared with APHRODITE. For MMD, the extreme precipitation rates over the southwest of the region are higher (by around $20 \mathrm{~mm} /$ day) than in GPM.

All the simulations, except Hh-Lv, show an apparent underestimation of the extreme precipitation rate (by up to about $60 \%$ ) over the region compared to the observational mean. The simulations with coarse horizontal resolutions, including Lh (Fig. 8e) and Lh-Lv (Fig. 8i), fail to capture the maximum extreme precipitation rate in the region. The $\mathrm{Hh}$ (Fig. 8f) shows obvious improvements in the simulated location of the maximum rate compared to Lh. Similar improvements are seen in Hv (Fig. 8h) compared to Lv (Fig. 8g); however, Hv shows a further underestimation of the extreme precipitation rate over the region. The Lh-Hv (Fig. 8j) simulations present the highest correlation with the observations compared to Lh-Lv, Hh-Lv (Fig. 8k) and Hh-Hv (Fig. 81). Also, Hh-Lv exhibits the best performance in simulating the maximum rate on the east coast and the lowest RMSE in general. Increases in both the horizontal and vertical resolutions (Hh-Hv) also show apparent improvement in the simulation of extreme precipitation along the east coast compared 
(a) MMD

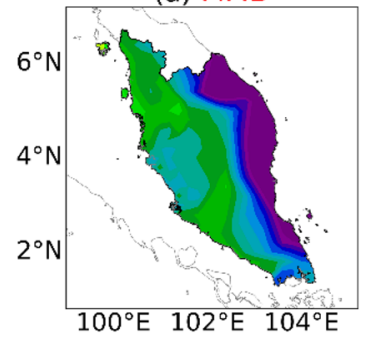

(e) Lh

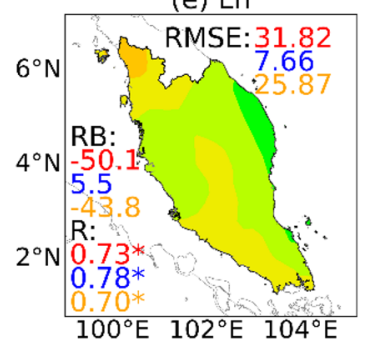

(i) Lh-LV

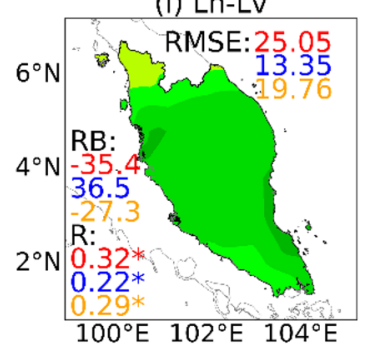

(b) APHRODITE

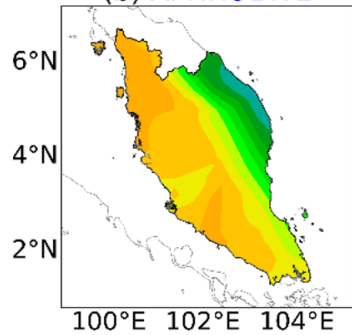

(f) $\mathrm{Hh}$

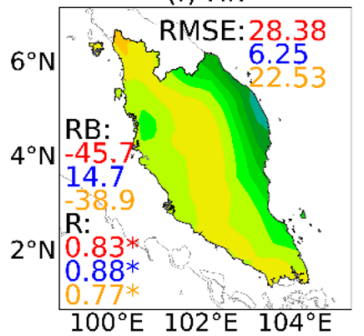

(j) $\mathrm{Lh}-\mathrm{HV}$

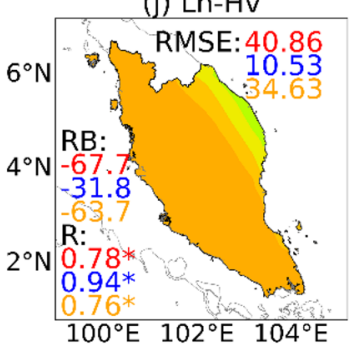

(c) GPM

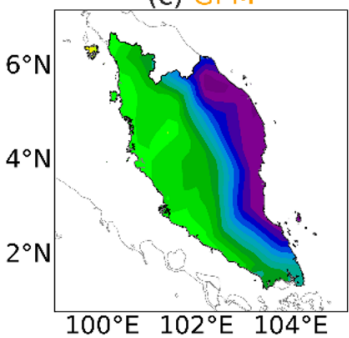

(g) LV

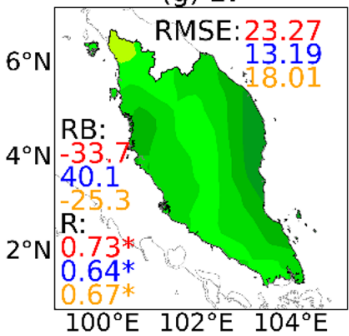

(k) Hh-Lv

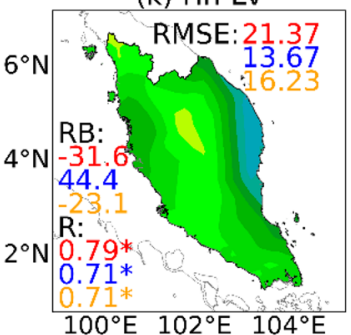

(d) Obs. Mean

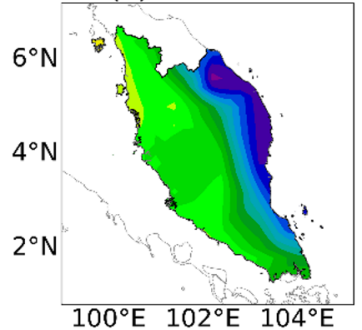

(h) HV

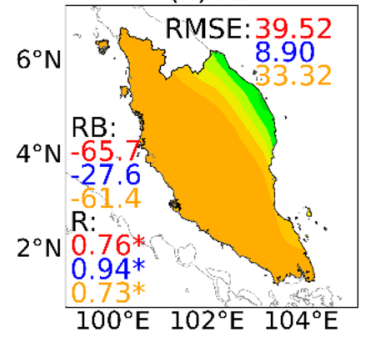

(I) $\mathrm{Hh}-\mathrm{HV}$

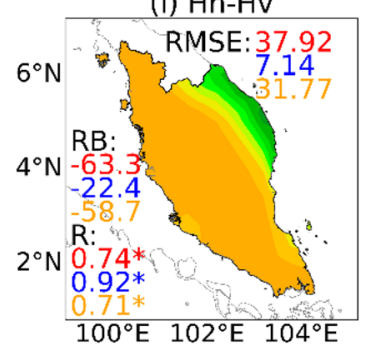

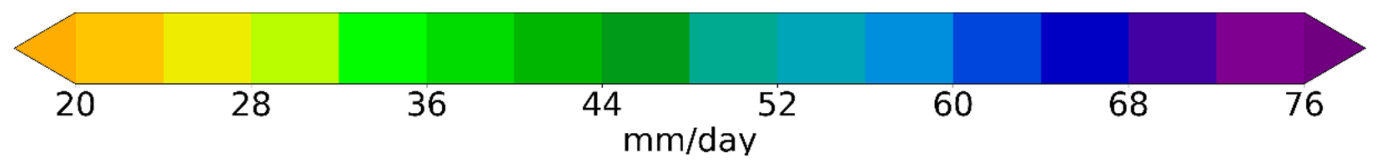

Fig. 8 As Fig. 3, but for the 95th percentile maximum daily precipitation rate during the northeast monsoon seasons (November to February, NDJF) for the period 2001-2014

to simulations with increased vertical resolutions alone, although the correlation with observations is not improved. $\mathrm{Hh}-\mathrm{Hv}$ also shows an obvious underestimation of extreme precipitation.

In summary, increased model resolution horizontally and vertically and yield a better-simulated pattern of extreme precipitation rate during the northeast monsoon seasons. Also, the GCMs with coarser horizontal resolutions tend to produce a weaker extreme precipitation rate. In contrast, stronger extreme precipitation rates are found in simulations with coarser vertical resolutions.

\subsection{Large-scale environments in the different monsoon seasons}

To further understand the source of any model biases in the simulated precipitation and the associated extreme events discussed in the previous section, in this section the precipitation-associated environmental fields of the monsoon seasons from the HighResMIP models are evaluated through their comparison to the four reanalysis datasets.

\subsubsection{Northeast monsoon season}

Moisture transport and the associated divergence field during the Northeast monsoon season are shown in Fig. 9. The reanalysis datasets illustrate strong moisture transport (up to $400 \mathrm{~kg} \mathrm{~m}^{-1} \mathrm{~s}^{-1}$ ) by the Northeast monsoon flow. The passage of the monsoon flow shows a region of weak horizontal divergence (up to $1.2 \times 10^{-4} \mathrm{~kg} \mathrm{~m}^{-2} \mathrm{~s}^{-1}$ ). For ERA5 (Fig. 9a), a narrow convergence belt associated with orographic blocking is seen near the east coast of Peninsular Malaysia. The orographic blocking on the windward side of the Titiwangsa Mountains across the west of the peninsula also causes a strong moisture convergence belt (up to $3.2 \times 10^{-4} \mathrm{~kg} \mathrm{~m}^{-2} \mathrm{~s}^{-1}$ ). A strong divergence belt (up to 

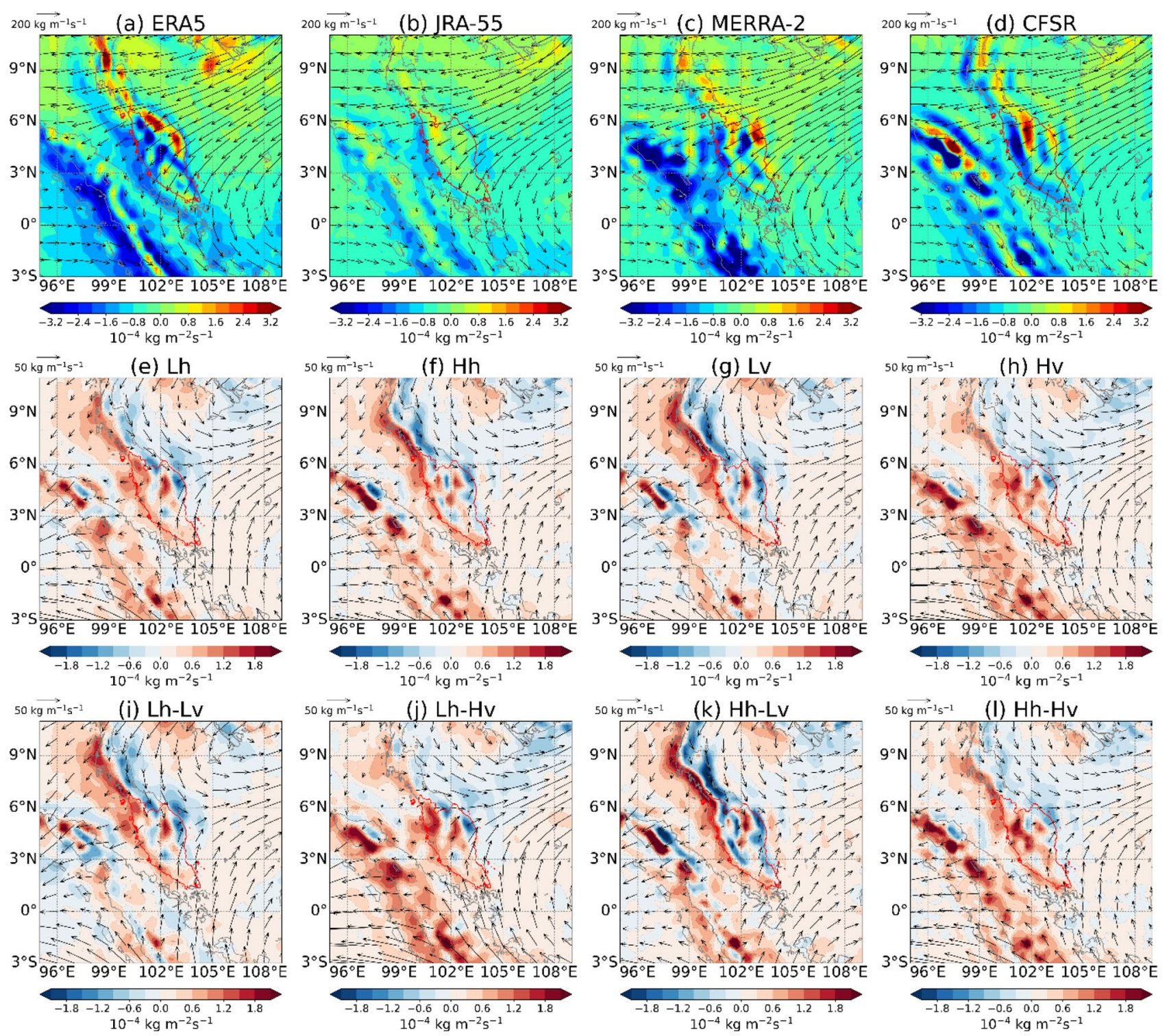

Fig. 9 NDJF-mean fields of the vertically integrated water vapor transport (IVT, vectors) and its horizontal convergence (positive shaded) and divergence (negative shaded) for the period 1980-2014

$3.2 \times 10^{-4} \mathrm{~kg} \mathrm{~m}^{-2} \mathrm{~s}+$ ) associated with the flow diversion is seen on the windward side of the East Coast Range. These characteristics of the wind-topography interaction are also shown by NCEP-CFSR (Fig. 9d). However, the convergence belt near the east coast is not apparently seen in MERRA-2 (Fig. 9c) and JRA55 (Fig. 9b) shows smaller magnitudes of moisture convergence/divergence compared to the other reanalyses. This may be due to the relatively coarse resolution in these two datasets, which limit fine-scale windtopography interactions. The following section assesses the performance of GCMs in simulating large-scale environments against the ensemble mean of all the reanalysis datasets. Although NCEP-CFSR and JRA55 are at a coarser

in four reanalysis datasets (a-d) and the difference fields between each resolution group and the ensemble mean of reanalysis data $(\mathbf{e}-\mathbf{l})$

resolution of data assimilation, they are also taken into account for incorporating more data sources so as to better consider the uncertainties in the data assimilation process, including the different model configuration, bias correction schemes and the different choice of observational data to be assimilated (Bengtsson et al. 2004; Dee et al. 2011).

The difference between the simulations of different resolution groups and the ensemble mean of the four reanalysis datasets indicate an underestimation (by up to about $60-70 \mathrm{~kg} \mathrm{~m}^{-2} \mathrm{~s}^{-1}$ ) of the moisture transport by the Northeast monsoon in all the model simulations (Fig. 9e-1). As a result, the flow diversion is weaker in all the simulations, which causes a moisture convergence bias near 
the east coast. These biases become less obvious in the simulations with high vertical resolution (e.g. Hv, Hh-Hv) compared to those with low vertical resolutions (e.g. Lv, $\mathrm{Hh}-\mathrm{Lv}$ ), implying an improvement in the simulated moisture transport and divergence of the Northeast monsoon. This explains the improved precipitation simulation in NDJF due to the increased vertical resolution as shown in Fig. 5b. However, the increase of vertical resolution also leads to a higher divergence bias near the west coast of the peninsula, which partly explains the underestimated extreme precipitation rate over the west in the simulations with high vertical resolutions as shown in Fig. 8. No apparent improvement in the simulated moisture transport is seen in the simulations with relatively high horizontal resolution compared to those with coarse resolutions. This is partly consistent with the study of Demory et al. (2014) suggesting that the simulated circulation associated with the global water budget in GCMs is insensitive to varying horizontal resolutions.

The vertical velocity is considered as an important environmental indicator of precipitation in Malaysia (Mahmud et al. 2020) and more widely in the tropics. Here, the vertical velocity fields at $850 \mathrm{hPa}$ from the HighResMIP models are examined. During the northeast monsoon seasons, the east coast of Peninsular Malaysia is dominated by an intense ascent (up to $9-15 \times 10^{-2} \mathrm{~Pa} \mathrm{~s}^{-1}$ ) of the northeasterly winds over coastal orography as shown by the reanalysis datasets (Fig. 10a-d). ERA5 and CFSR also show intense ascent (up to $15 \times 10^{-2} \mathrm{~Pa} \mathrm{~s}^{-1}$ ) on the windward side of the Titiwangsa Mountains, mid-west of the peninsula. This feature is,
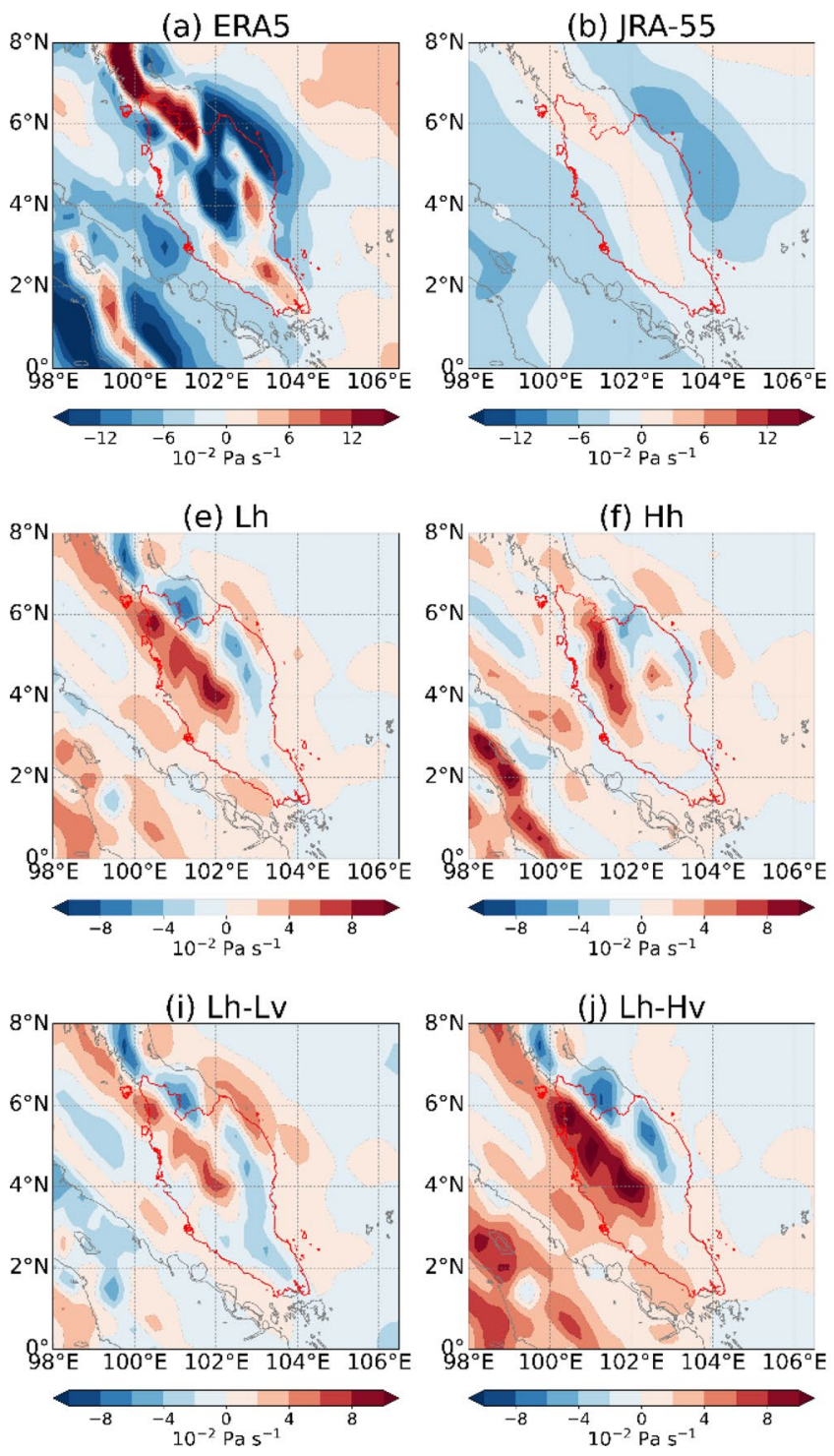
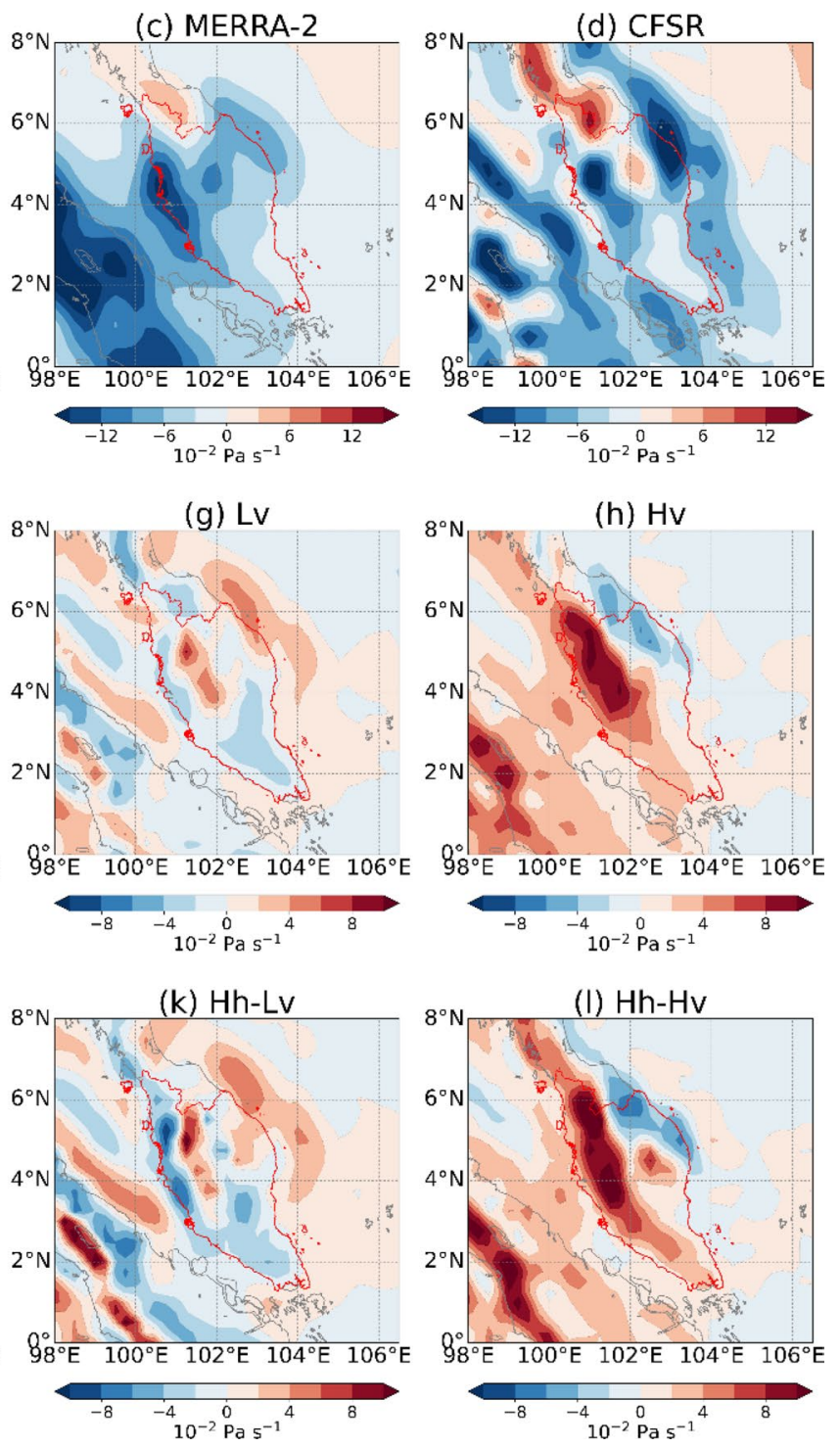

Fig. 10 NDJF-mean fields of vertical velocity at $850 \mathrm{hPa}$ (positive: downward motion) for the period 1979-2014 in four reanalysis datasets (a-d) and the difference fields between each resolution group and the ensemble mean of reanalysis data (e-l) 
however, not obvious in JRA-55 and MERRA-2, which may again be due to their relatively coarse horizontal resolutions.

All the model simulations (Fig. 10e-l) except $\mathrm{Hh}-\mathrm{Lv}$ exhibit an underestimate of ascent (by up to $8 \times 10^{-2} \mathrm{~Pa} \mathrm{~s}^{-1}$ ) across the west of the peninsula. This bias is more obvious in simulations with relatively high vertical resolutions (e.g. $\mathrm{Hv}, \mathrm{Lh}-\mathrm{Hv}$ and $\mathrm{Hh}-\mathrm{Hv}$ ) compared to those with low vertical resolutions (e.g. Lv, Lh-Lv and $\mathrm{Hh}-\mathrm{Lv}$ ). The simulations with high horizontal resolutions $(\mathrm{Hh})$ show some reduction of this bias compared to Lh, though such an improvement is as apparent for Hh-Hv compared to Lh-Hv. The bias may be due to the overly weak strength of the Northeast monsoon (Fig. 9e-1). Such a bias also partly explains the underestimated precipitation during NDJF (Fig. 4 and Fig. 8), especially for simulations with high vertical resolutions.
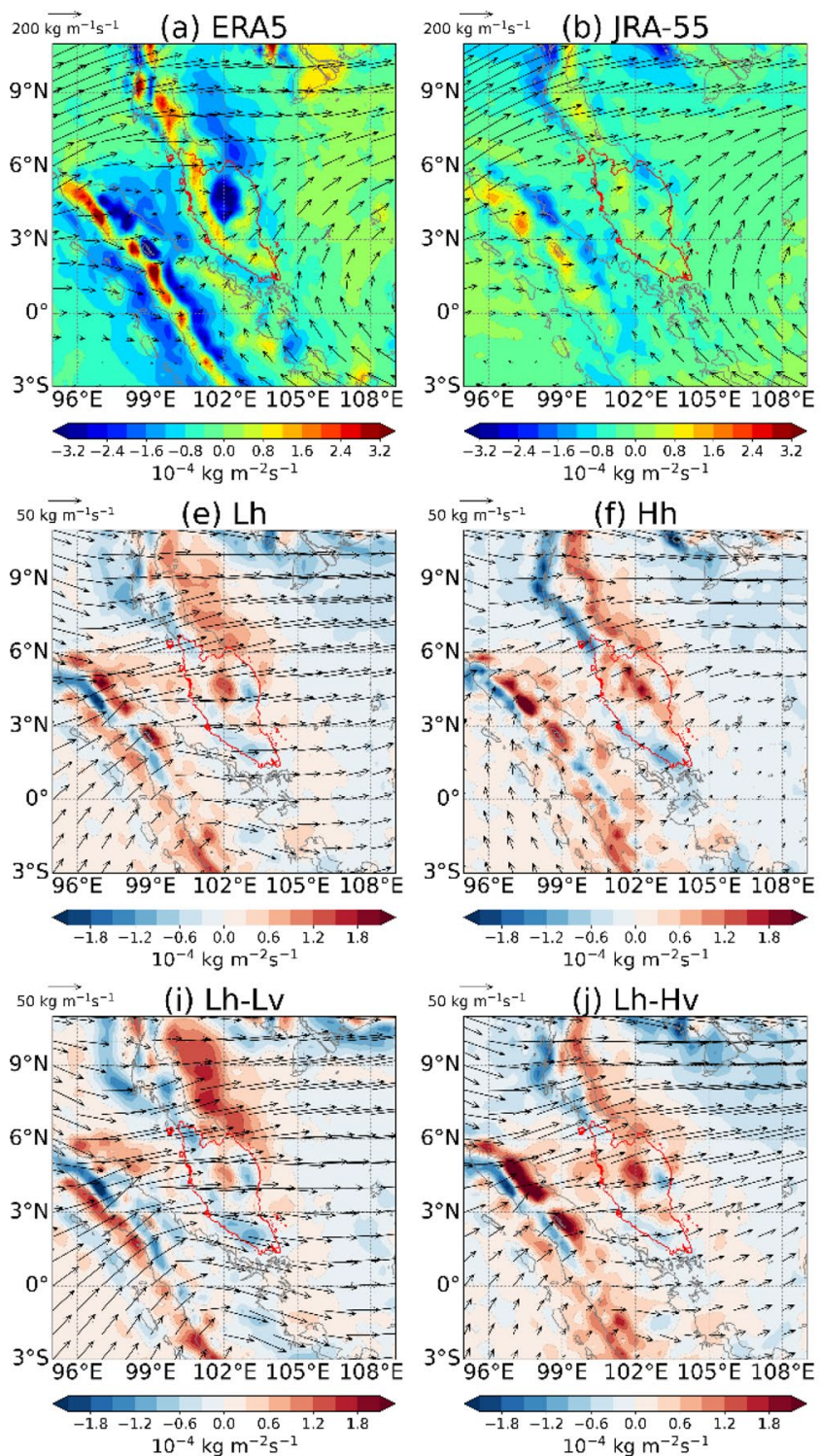
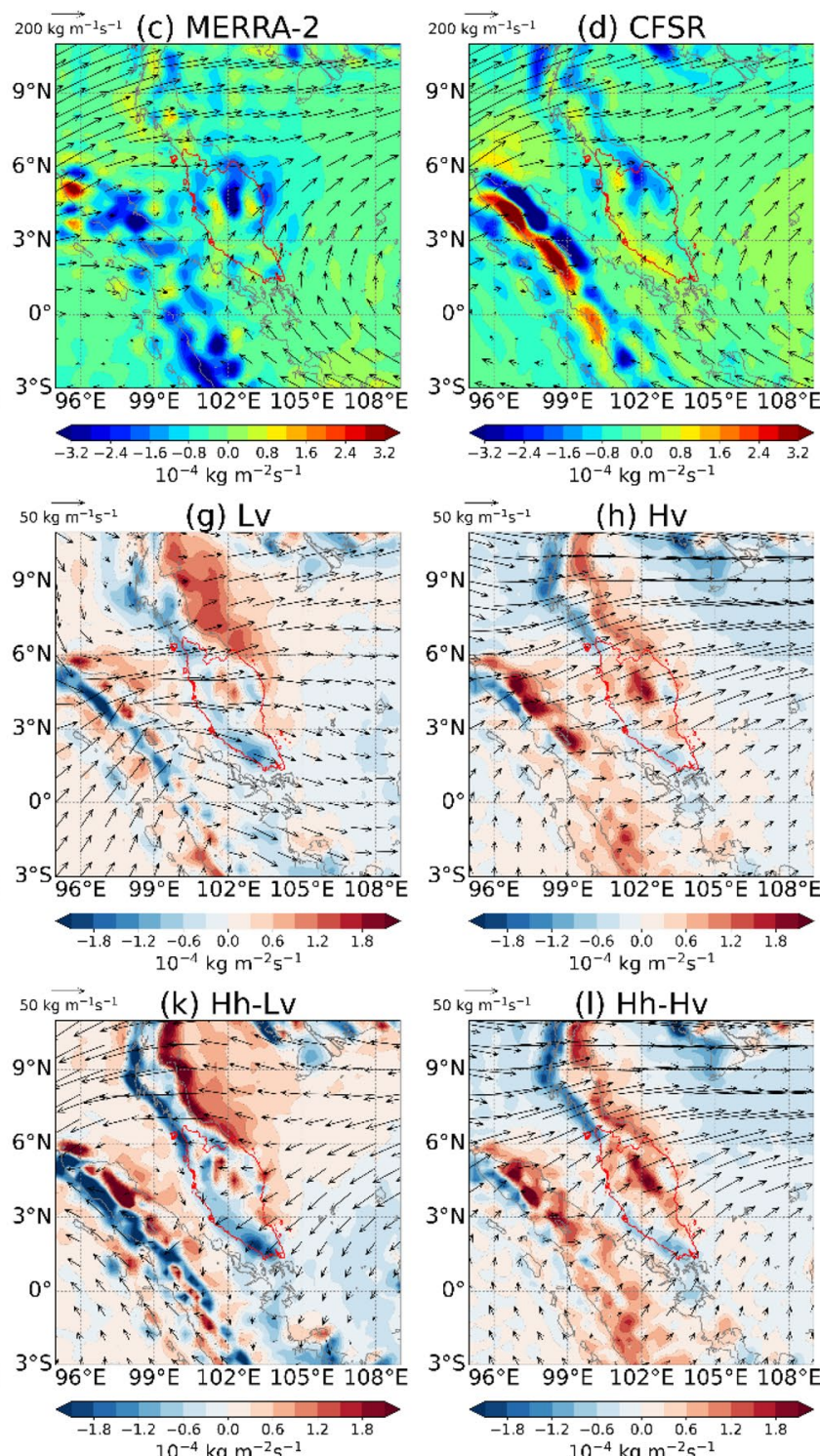

Fig. 11 Same as Fig. 9, but for the MJJA-mean fields 
region and an overestimate of convergence in the northwest. Similar biases are shown in $\mathrm{Hh}, \mathrm{Lv}, \mathrm{Hv}, \mathrm{Lh}-\mathrm{Lv}, \mathrm{Lh}-\mathrm{Hv}$ and $\mathrm{Hh}-\mathrm{Hv}$. These biases can induce an overestimate of precipitation during MJJA in the west of Peninsular Malaysia, which are consistent with the overestimated negative anomalies of precipitation in the region for NDJF relative to MJJA as shown in Fig. 4e-1. The Hh-Lv simulations (Fig. 11k), however, show the smallest biases in moisture transport, which possibly explains their superior performance in simulating the pattern of precipitation difference between MJJA and NDJF (Fig. 4k).

Figure 12 shows the vertical velocity fields during the Southwest monsoon season (MJJA). A relatively intense ascent (up to 5-12.5 $\times 10^{-2} \mathrm{~Pa} \mathrm{~s}^{-1}$ ) is found in the mid-north of Peninsular Malaysia (Fig. 12a-d) due to the influence of the westerly monsoonal flow to the north of Sumatra and the cross-equatorial southwesterly flow over the south of the peninsula (Fig. 11a-d). Although all the simulations (Fig. 12e-1) show a weaker ascent (up to $6-10 \times 10^{-2} \mathrm{~Pa} \mathrm{~s}^{-1}$ ) over the mid-north of the peninsula, some overestimation of the ascent is seen across the west coast. These biases, combined with the overestimated moisture convergence in this region (Fig. 12e-1), may explain the overestimated precipitation during the season (Fig. 2b), especially for simulations with coarse vertical resolutions ( $\mathrm{Lv}, \mathrm{Lh}-\mathrm{Lv}$ and $\mathrm{Hh}-\mathrm{Lv}$ ).

In general, the simulations of the precipitation-related environmental fields for different resolution groups exhibit some similar biases with respect to the ensemble mean of the four reanalysis datasets. These include the overly weak moisture transport by the Northeast monsoon flow in NDJF and (a) ERA5

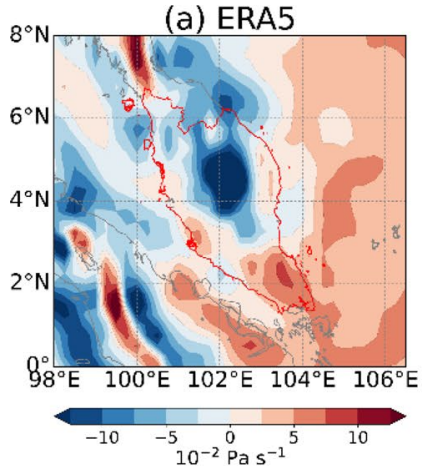

(e) Lh

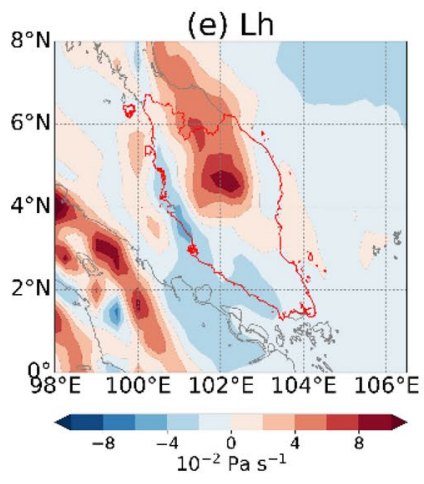

(i) Lh-Lv

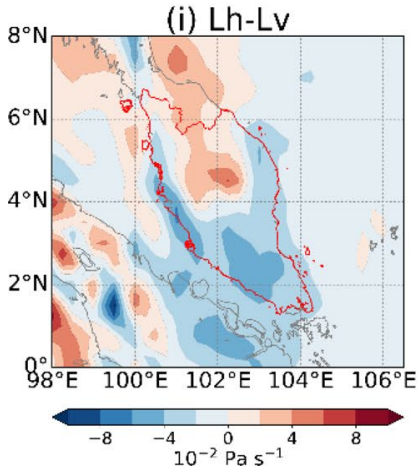

(b) JRA-55

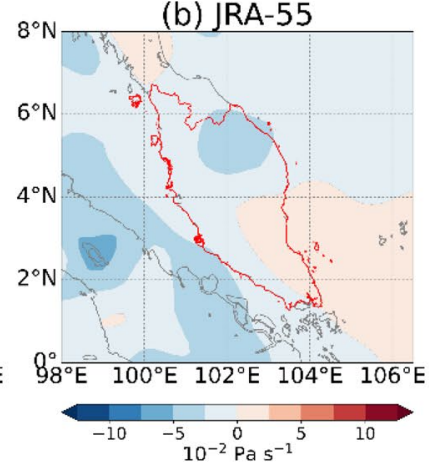

(f) $\mathrm{Hh}$
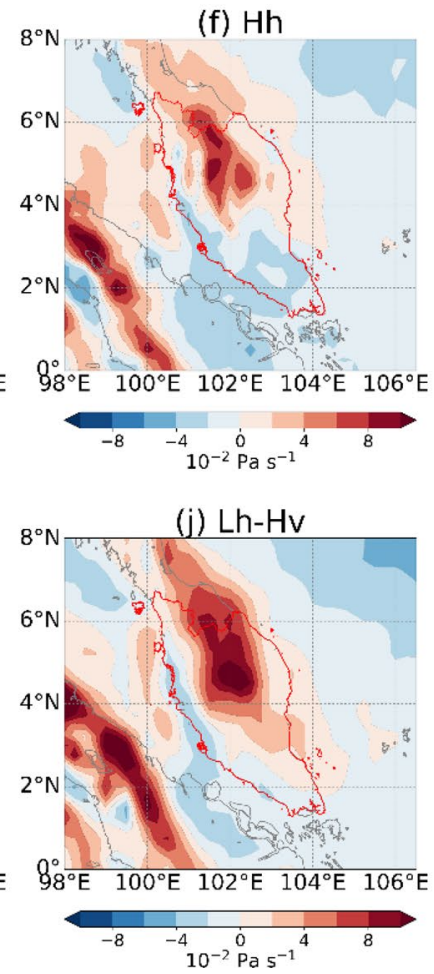

(c) MERRA-2

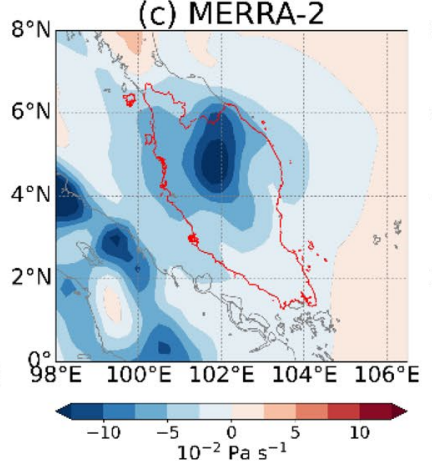

(g) LV

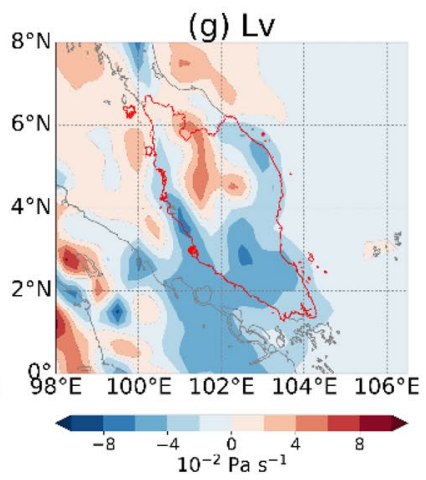

(k) Hh-Lv

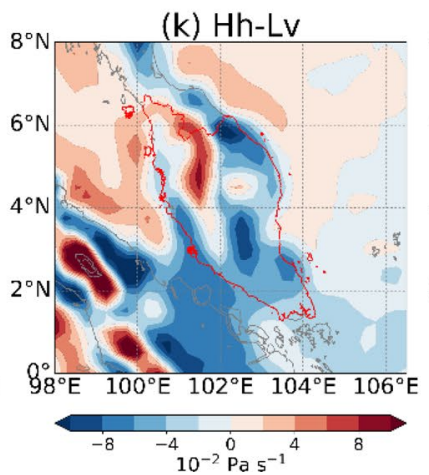

(d) CFSR

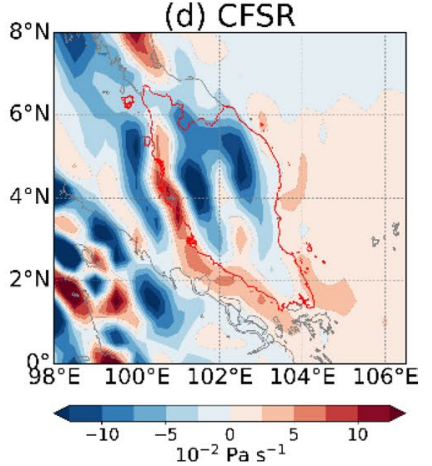

(h) $\mathrm{Hv}$
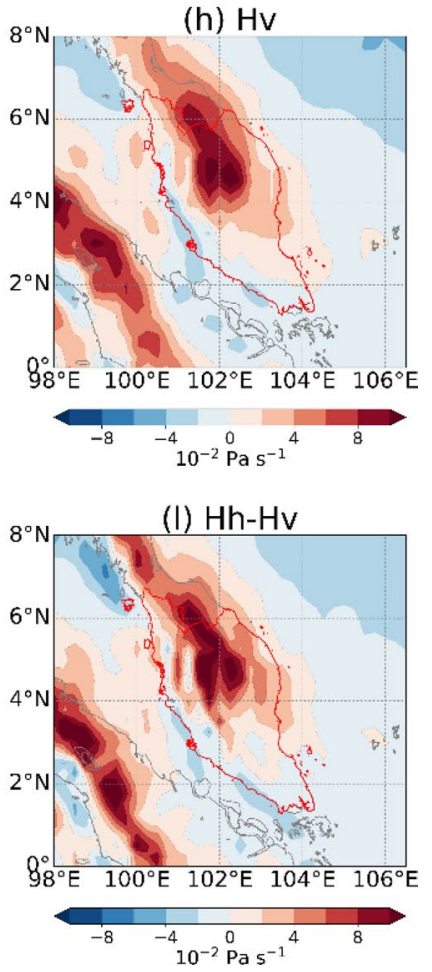

Fig. 12 Same as Fig. 10, but for the MJJA-mean fields 
the strength of Southwest monsoon flow is overestimated. Also, for most of the simulations, the ascent in the lower troposphere for different seasons are generally underestimated over the region. The simulations with high horizontal resolutions show some improvements in simulating the lower-tropospheric vertical velocity and moisture transport/ divergence in different seasons. However, greater biases are seen in simulations with relatively high resolutions compared to those with low vertical resolutions.

\section{Summary and discussion}

This study has evaluated the performance of the CMIP6 HighResMIP experiments in simulating monsoonal precipitation and associated large-scale environments over Peninsular Malaysia and the impact of varying horizontal and vertical resolution on model skill. The analyses have grouped the model simulations by horizontal and vertical resolution. Compared to simulations at coarser resolutions, the higher horizontal and vertical resolution versions of the HighResMIP models show improved ability to simulate the total precipitation in different monsoon seasons during the period 2001-2014 compared with three observed precipitation datasets. Improvements in the simulated relationship between precipitation and monsoon intensity in different monsoon seasons are also achieved in simulations at increased resolutions, especially for the southwest monsoon seasons. The results also show that the simulations with higher horizontal and vertical resolutions from the HighResMIP experiments are more capable of representing the observed annual cycle and spatial patterns of precipitation compared to the low horizontal and vertical resolution simulations. Similar improvements associated with increased horizontal resolution have been found in previous studies based on RCM simulations over the CORDEX-SEAsia domain (Tangang et al. 2020) and East Asia (e.g., Jin et al. 2016); however, further study is required to compare the performance of HighResMIP with the RCM simulations of CORDEX-SEAsia so that their advantages and disadvantages can be better understood. Jain et al. (2019) considered these improvements to be associated with improved lowlevel dynamics and better-resolved topography. These findings also support the study of Lindzen and Fox-Rabinovitz (1989) suggesting that the increase in horizontal and vertical model resolutions ought to be set consistently for a reasonable Rossby ratio between vertical and horizontal scales in quasi-geostrophic flow. However, it is still unclear whether the improvement in the seasonal mean precipitation is associated with better resolved synoptic weather systems associated with precipitation, such as the northeasterly cold surges and Borneo Vortices (Tangang et al. 2008; Koseki et al. 2014; Liang et al. 2021), rather than the mean circulation patterns being better represented. In another study of the authors, increases in horizontal resolution were found to significantly improve the simulation of Borneo Vortices using the HighResMIP experiments from the HadGEM3-GC31 model (Liang et al. 2021). However, it is still difficult to fully explore these weather systems within all the HighResMIP ensemble members due to limited data availability.

The analysis of the annual cycle of precipitation shows that all the HighResMIP experiments can capture the observed precipitation peaks of the year during the Northeast monsoon seasons. However, all the simulations, particularly for those with low vertical resolutions, tend to overestimate the precipitation amount during the Southwest monsoon season. The simulations at lower vertical resolutions are also found to produce higher annual mean precipitation and extreme precipitation in NDJF than those at higher vertical resolutions and lead to overestimated precipitation, which can be explained by the stronger vertical ascent in the different monsoon seasons. These findings are partly consistent with the study of Volosciuk et al. (2015), suggesting that coarser vertical resolution in a GCM can cause an equatorward shift of extreme precipitation in the tropics, while the physical mechanism behind this finding remains unclear. In addition, the total precipitation amount and extreme precipitation rates during the Northeast monsoon season are also generally underestimated by all the simulations. These biases are associated with the overly strong (weak) moisture transport by the Southwest (Northeast) monsoon flows. Although increases in both the horizontal and vertical resolution can yield a better representation in general of the observed temporal and spatial distribution of precipitation, the large-scale environments in the low vertical resolution versions generally present fewer biases with respect to the ensemble mean of the reanalysis data. Previous research has also reported similar limitations of the increase of vertical resolution on improving the simulation of circulation features associated with precipitation. For instance, Xie et al. (2018) found that increasing vertical resolution can lead to greater underestimation of tropical high clouds and shallower penetration of deep convection as water vapor becomes more confined to the lower levels and less moisture being transported into the middle troposphere. However, due to the limited ensemble size and spatial resolution of the reanalysis data used here, the evaluation of the simulated large-scale environmental fields should be interpreted with caution.

This study has performed a classification of GCM experiments in terms of theirs horizontal and vertical resolutions to investigate the role of model resolution in the simulation of monsoonal precipitation. It should be noted that the sensitivity of precipitation to the different model groupings found here can be due to other factors, such as the different atmospheric dynamical core (e.g. Jang and Hong 2016; Yang et al. 2017) and physical parameterizations (e.g. Im 
et al. 2008; Juneng et al. 2016) used in the selected experiments. The limited sample size for each resolution group may also lead to uncertainties, especially for the $\mathrm{Hh}-\mathrm{Hv}$ simulations which only include four members, as the number of ensemble members for the high-resolution models are strongly limited by their computational cost. Moreover, we note that the selected observed precipitation datasets exhibit considerable uncertainties in the magnitude of precipitation, though similarities in spatial distribution are observed. Also, the selected climate reanalysis data contains uncertainties in their data assimilation methods. Although the use of the different observational and reanalysis datasets as verification data in this study help to understand the impact of the uncertainties and thus to improve the robustness of model evaluation.

This study has focused on climatological precipitation patterns. As such, one limitation of the study is the lack of analysis of the natural variability of precipitation over Peninsular Malaysia. Precipitation studies in the region have suggested a connection between the interannual variability of precipitation with the El Niño-Southern Oscillation (Wong et al. 2009; 2016; Tangang et al. 2017). The Indian Ocean Dipole has also been found to be associated with historical extreme precipitation events in the region (e.g. Tangang et al. 2008; Islam et al. 2018). Moreover, phases 3-5 of the Madden-Julian Oscillation are found to facilitate the low-level convergence and vertical velocity over the western Maritime Continent during boreal winter ( $\mathrm{Wu}$ and $\mathrm{Hsu}$ 2009; Oh et al. 2012), leading to strong intra-seasonal variability of deep convection and precipitation over the region (Peatman et al. 2014). In addition, deep convection strongly interacts with tropical waves, which leads to variability of precipitation at synoptic time scales (Ferrett et al. 2020). Precipitation over Peninsular Malaysia also exhibits strong diurnal variation with the peak of precipitation observed early in the evening (Varikoden et al. 2011). The ability of climate models to simulate variability at different temporal scales in this region is still not well understood and will be investigated in future model-based studies.

The research indicates some credibility in the use of highresolution simulations of HighResMIP for projecting the possible future changes of precipitation in a warmer climate, but these results make it clear that users should be aware of the fact that model performance varies depending on the phenomena of interest. Based on these simulations, future work will study projections of precipitation under greenhouse gas emission scenarios. One ongoing study based on HighResMIP is focusing on the simulation of Borneo Vortices and the associated precipitation over Malaysia in the present (Liang et al. 2021) and future climate. Another ongoing study uses the HighResMIP experiments as input to a river basin-scale hydrological model to investigate the combined impact of climate change and land use change on extreme hydrological events over Peninsular Malaysia (Tan et al. 2021). The model evaluation in this article will provide important information for future research based on the HighResMIP experiments.

Acknowledgements This research was supported by the Newton Fund of The Natural Environment Research Council: IMpacts of PRecipitation from Extreme StormS-Malaysia (IMPRESS-Malaysia, grant number: NE/S002707/1), and Ministry of Higher Education Malaysia (Grant Number: 203.PHUMANITI.6780001).

Data availability The $25-\mathrm{km}$ gridded daily mean precipitation over the Asian monsoon region from APHRODITE can be retrieved from the website (https://www.chikyu.ac.jp/precip/english/products.html). The $0.1^{\circ} \times 0.1^{\circ} \mathrm{GPM}$ multi-satellite precipitation product can be downloaded from the Earth Data webpage of the National Aeronautics and Space Administration (https://disc.gsfc.nasa.gov/datasets/GPM 3IMERGDF_06/summary?keywords=\%22IMERG\%20final\%22). The ERA5 climate reanalysis datasets can be downloaded from the website of the Copernicus Programme (https://cds.climate.copernicus.eu/ cdsapp\#!/dataset/). The JRA-55, MERRA-2 and NCEP-CFSR climate reanalysis datasets can be downloaded from the data node website of the Collaborative REAnalysis Technical Environment (CREATE) hosted by Lawrence Livermore National Laboratory (https://esgf-node. 1lnl.gov/projects/create-ip/). The used CMIP6 HighResMIP GCM data can be retrieved from the CMIP6 data node website hosted by Lawrence Livermore National Laboratory (https://esgf-node.llnl.gov/proje cts/cmip6/).

\section{Declarations}

Conflict of interest The authors declare that they have no conflict of interest.

Open Access This article is licensed under a Creative Commons Attribution 4.0 International License, which permits use, sharing, adaptation, distribution and reproduction in any medium or format, as long as you give appropriate credit to the original author(s) and the source, provide a link to the Creative Commons licence, and indicate if changes were made. The images or other third party material in this article are included in the article's Creative Commons licence, unless indicated otherwise in a credit line to the material. If material is not included in the article's Creative Commons licence and your intended use is not permitted by statutory regulation or exceeds the permitted use, you will need to obtain permission directly from the copyright holder. To view a copy of this licence, visit http://creativecommons.org/licenses/by/4.0/.

\section{References}

Ajibola FO, Zhou B, Gnitou GT, Onyejuruwa A (2020) Evaluation of the performance of cmip6 highresmip on west african precipitation. Atmosphere 11:1053. https://doi.org/10.3390/atmos 11101053

Alfeld P (1984) A trivariate clough-tocher scheme for tetrahedral data. Comput Aided Geom Des 1:169-181. https://doi.org/10.1016/ 0167-8396(84)90029-3

Amin MZM, Shaaban AJ, Ercan A et al (2017) Future climate change impact assessment of watershed scale hydrologic processes in Peninsular Malaysia by a regional climate model coupled with a physically-based hydrology modelo. Sci Total Environ 575:1222. https://doi.org/10.1016/j.scitotenv.2016.10.009 
Arakawa O, Kitoh A (2005) Rainfall diurnal variation over the Indonesian Maritime Continent simulated by $20 \mathrm{~km}$-mesh GCM. SOLA 1:109-112. https://doi.org/10.2151/sola.2005-029

Bador M, Boé J, Terray L et al (2020) Impact of higher spatial atmospheric resolution on precipitation extremes over land in global climate models. J Geophys Res Atmos. https://doi.org/10.1029/ 2019JD032184

Bengtsson L, Hagemann S, Hodges KI (2004) Can climate trends be calculated from reanalysis data? J Geophys Res Atmos 109:1-8. https://doi.org/10.1029/2004JD004536

Bowden JH, Otte TL, Nolte CG, Otte MJ (2012) Examining interior grid nudging techniques using two-way nesting in the WRF model for regional climate modeling. J Clim 25:2805-2823. https://doi.org/10.1175/JCLI-D-11-00167.1

Camerlengo A, Saadon M, Aziz A, Othman M (1998) Monthly distribution of precipitation in Peninsular Malaysia. Pertanika J Sci Technol 6:59-70

Chan NW (1997) Increasing flood risk in Malaysia: causes and solutions. Disaster Prev Manag Int J 6:72-86. https://doi.org/10. 1108/09653569710164035

Chan NW (2015) Challenges in flood disasters management in Malaysia. Universiti Sains Malaysia, Penang

Chang CP, Wang Z, McBride J, Liu CH (2005) Annual cycle of Southeast Asia-Maritime continent rainfall and the asymmetric monsoon transition. J Clim 18:287-301. https://doi.org/10. 1175/JCLI-3257.1

Chen TC, Tsay JD, Yen MC, Matsumoto J (2013) The winter rainfall of malaysia. J Clim 26:936-958. https://doi.org/10.1175/ JCLI-D-12-00174.1

Chenoli SN, Jayakrishnan PR, Samah AA et al (2018) Southwest monsoon onset dates over Malaysia and associated climatological characteristics. J Atmos Sol-Terr Phys 179:81-93. https://doi. org/10.1016/j.jastp.2018.06.017

Chin KS, Tan KW (2018) Evaluation of SRE Scenarios for Penang, Selangor and Johor in Peninsular Malaysia using PRECIS Regional Climate Model (RCM). In: E3S Web of Conferences. EDP Sciences, $\mathrm{p} 05020$

Chung JX, Juneng L, Tangang F, Jamaluddin AF (2018) Performances of BATS and CLM land-surface schemes in RegCM4 in simulating precipitation over CORDEX Southeast Asia domain. Int $\mathbf{J}$ Climatol 38:794-810. https://doi.org/10.1002/joc.5211

Dee DP, Källén E, Simmons AJ, Haimberger L (2011) Comments on "Reanalyses Suitable for Characterizing Long-Term Trends." Bull Am Meteorol Soc 92:65-70. https://doi.org/10.1175/2010B AMS3070.1

Demory ME, Vidale PL, Roberts MJ et al (2014) The role of horizontal resolution in simulating drivers of the global hydrological cycle. Clim Dyn 42:2201-2225. https://doi.org/10.1007/ s00382-013-1924-4

Demory ME, Berthou S, Fernández J et al (2020) European daily precipitation according to EURO-CORDEX regional climate models (RCMs) and high-resolution global climate models (GCMs) from the High-Resolution Model Intercomparison Project (HighResMIP). Geosci Model Dev 13:5485-5506. https://doi.org/10. 5194/gmd-13-5485-2020

Deni SM, Suhaila J, Wan Zin WZ, Jemain AA (2010) Spatial trends of dry spells over Peninsular Malaysia during monsoon seasons. Theor Appl Climatol 99:357-371. https://doi.org/10.1007/ s00704-009-0147-4

Diya SG, Gasim MB, Toriman ME, Abdullahi MG (2014) Floods in Malaysia: Historical reviews, causes, effects and mtigations approach. Int J Interdiscip Res Innov 2:59-65. https://doi.org/ 10.5897/AJBx 10.009
Dong T, Dong W (2021) Evaluation of extreme precipitation over Asia in CMIP6 models. Clim Dyn 1:1-19. https://doi.org/10.1007/ s00382-021-05773-1

Druyan LM, Fulakeza M, Lonergan P (2008) The impact of vertical resolution on regional model simulation of the west African summer monsoon. Int J Climatol 28:1293-1314. https://doi.org/10. 1002/joc. 1636

Eyring V, Bony S, Meehl GA et al (2016) Overview of the Coupled Model Intercomparison Project Phase 6 (CMIP6) experimental design and organization. Geosci Model Dev 9:1937-1958. https://doi.org/10.5194/gmd-9-1937-2016

Farr TG, Rosen PA, Caro E et al (2007) The shuttle radar topography mission. Rev Geophys 45:1-33. https://doi.org/10.1029/2005R G000183

Feng L, Zhou T, Wu B et al (2011) Projection of future precipitation change over China with a high-resolution global atmospheric model. Adv Atmos Sci 28:464-476. https://doi.org/10.1007/ s00376-010-0016-1

Ferrett S, Yang GY, Woolnough SJ et al (2020) Linking extreme precipitation in Southeast Asia to equatorial waves. Q J R Meteorol Soc 146:665-684. https://doi.org/10.1002/qj.3699

Fujita M, Sato T (2017) Observed behaviours of precipitable water vapour and precipitation intensity in response to upper air profiles estimated from surface air temperature. Sci Rep 7:1-6. https://doi.org/10.1038/s41598-017-04443-9

Gelaro R, McCarty W, Suárez MJ et al (2017) The modern-era retrospective analysis for research and applications, version 2 (MERRA-2). J Clim 30:5419-5454. https://doi.org/10.1175/ JCLI-D-16-0758.1

Ghimire S, Choudhary A, Dimri AP (2018) Assessment of the performance of CORDEX-South Asia experiments for monsoonal precipitation over the Himalayan region during present climate: part I. Clim Dyn 50:2311-2334. https://doi.org/10.1007/ s00382-015-2747-2

Haarsma R, Acosta M, Bakhshi R et al (2020) HighResMIP versions of EC-Earth: EC-Earth3P and EC-Earth3P-HR - Description, model computational performance and basic validation. Geosci Model Dev 13:3507-3527. https://doi.org/10.5194/gmd-13-3507-2020

Haarsma RJ, Roberts MJ, Vidale PL et al (2016) High Resolution Model Intercomparison Project (HighResMIP v1.0) for CMIP6. Geosci Model Dev 9:4185-4208. https://doi.org/10.5194/ gmd-9-4185-2016

Hai OS, Samah AA, Chenoli SN et al (2017) Extreme rainstorms that caused devastating flooding across the east coast of Peninsular Malaysia during November and December 2014. Weather Forecast 32:849-872. https://doi.org/10.1175/WAF-D-16-0160.1

Harris LM, Durran DR (2010) An idealized comparison of one-way and two-way grid nesting. Mon Weather Rev 138:2174-2187. https://doi.org/10.1175/2010MWR3080.1

Hassan Z, Shamsudin S, Harun S et al (2015) Suitability of ANN applied as a hydrological model coupled with statistical downscaling model: a case study in the northern area of Peninsular Malaysia. Environ Earth Sci 74:463-477. https://doi.org/10. 1007/s12665-015-4054-y

Hersbach H, Bell B, Berrisford P et al (2020) The ERA5 global reanalysis. Q J R Meteorol Soc 146:1999-2049. https://doi.org/10. 1002/qj.3803

Huffman G, Bolvin DT, Braithwaite D, et al (2015) Algorithm Theoretical Basis Document (ATBD) Version 4.5: NASA Global Precipitation Measurement (GPM) Integrated Multi-satellitE Retrievals for GPM (IMERG). Greenbelt

Im E-S, Ahn J-B, Remedio AR, Kwon W-T (2008) Sensitivity of the regional climate of East/Southeast Asia to convective parameterizations in the RegCM3 modelling system. Part 1: Focus on 
the Korean peninsula. Int J Climatol 28:1861-1877. https://doi. org/10.1002/joc. 1664

Inness PM, Slingo JM, Woolnough SJ et al (2001) Organization of tropical convection in a GCM with varying vertical resolution; Implications for the simulation of the Madden-Julian oscillation. Clim Dyn 17:777-793. https://doi.org/10.1007/s003820000148

Iorio JP, Duffy PB, Govindasamy B et al (2004) Effects of model resolution and subgrid-scale physics on the simulation of precipitation in the continental United States. Clim Dyn 23:243-258. https://doi.org/10.1007/s00382-004-0440-y

Islam MA, Chan A, Ashfold MJ et al (2018) Effects of El-Niño, Indian Ocean Dipole, and Madden-Julian Oscillation on surface air temperature and rainfall anomalies over Southeast Asia in 2015. Atmosphere 9:352. https://doi.org/10.3390/atmos9090352

Jain S, Mishra SK, Salunke P, Sahany S (2019) Importance of the resolution of surface topography vis-à-vis atmospheric and surface processes in the simulation of the climate of Himalaya-Tibet highland. Clim Dyn 52:4735-4748. https://doi.org/10.1007/ s00382-018-4411-0

Jamaluddin AF, Tangang F, Chung JX et al (2018) Investigating the mechanisms of diurnal rainfall variability over Peninsular Malaysia using the non-hydrostatic regional climate model. Meteorol Atmos Phys 130:611-633. https://doi.org/10.1007/ s00703-017-0541-x

Jang J, Hong SY (2016) Comparison of simulated precipitation over East Asia in two regional models with hydrostatic and nonhydrostatic dynamical cores. Mon Weather Rev 144:3579-3590. https://doi.org/10.1175/MWR-D-15-0428.1

Ji X, Li Y, Luo X et al (2020) Evaluation of bias correction methods for APHRODITE data to improve hydrologic simulation in a large Himalayan basin. Atmos Res 242:1-18. https://doi.org/10.1016/j. atmosres.2020.104964

Jin EK, Choi I-J, Kim S-Y, Han J-Y (2016) Impact of model resolution on the simulation of diurnal variations of precipitation over East Asia. J Geophys Res Atmos 121:1652-1670. https://doi.org/10. 1002/2015JD023948

Juneng L, Tangang F, Chung J et al (2016) Sensitivity of Southeast Asia rainfall simulations to cumulus and air-sea flux parameterizations in RegCM4. Clim Res 69:59-77. https://doi.org/10.3354/ cr01386

Juneng L, Tangang FT, Kang H et al (2010) Statistical downscaling forecasts for winter monsoon precipitation in Malaysia using multimodel output variables. J Clim 23:17-27. https://doi.org/ 10.1175/2009JCLI2873.1

Kamworapan S, Surussavadee C (2019) Evaluation of CMIP5 global climate models for simulating climatological temperature and precipitation for southeast Asia. Adv Meteorol. https://doi.org/ $10.1155 / 2019 / 1067365$

Kim IW, Oh J, Woo S, Kripalani RH (2019) Evaluation of precipitation extremes over the Asian domain: observation and modelling studies. Clim Dyn 52:1317-1342. https://doi.org/10.1007/ s00382-018-4193-4

Kobayashi S, Ota Y, Harada Y et al (2015) The JRA-55 reanalysis: general specifications and basic characteristics. J Meteorol Soc Japan 93:5-48. https://doi.org/10.2151/jmsj.2015-001

Kong X, Wang A, Bi X et al (2020) Effects of horizontal resolution on hourly precipitation in agcm simulations. J Hydrometeorol 21:643-670. https://doi.org/10.1175/JHM-D-19-0148.1

Kopparla P, Fischer EM, Hannay C, Knutti R (2013) Improved simulation of extreme precipitation in a high-resolution atmosphere model. Geophys Res Lett 40:5803-5808. https://doi.org/10.1002/ 2013GL057866

Koseki S, Koh TY, Teo CK (2014) Borneo vortex and mesoscale convective rainfall. Atmos Chem Phys 14:4539-4562. https://doi. org/10.5194/acp-14-4539-2014
Kotsuki S, Tanaka K (2013) Uncertainties of precipitation products and their impacts on runoff estimates through hydrological land surface simulation in Southeast Asia. Hydrol Res Lett 7:79-84. https://doi.org/10.3178/hrl.7.79

Kwan MS, Tangang FT, Juneng L (2014) Present-day regional climate simulation over Malaysia and western Maritime Continent region using PRECIS forced with ERA40 reanalysis. Theor Appl Climatol 115:1-14. https://doi.org/10.1007/s00704-013-0873-5

Liang J, Catto JL, Hawcroft $M$ et al (2021) Climatology of Borneo Vortices in the HadGEM3-GC31 general circulation model. J Clim 34:3401-3419. https://doi.org/10.1175/jcli-d-20-0604.1

Lindzen RS, Fox-Rabinovitz M (1989) Consistent vertical and horizontal resolution. Mon Weather Rev 117:2575-2583. https://doi.org/ 10.1175/1520-0493(1989)117\%3c2575:CVAHR\%3e2.0.CO;2

Luo X, Fan X, Ji X, Li Y (2020) Evaluation of corrected APHRODITE estimates for hydrological simulation in the Yarlung TsangpoBrahmaputra River Basin. Int J Climatol 40:4158-4170. https:// doi.org/10.1002/joc.6449

Maggioni V, Sapiano MRP, Adler RF (2016) Estimating uncertainties in high-resolution satellite precipitation products: systematic or random error? J Hydrometeorol 17:1119-1129. https://doi.org/ 10.1175/JHM-D-15-0094.1

Mahmud MR, Yusof AAM, Reba M, Hashim M (2020) Mapping the daily rainfall over an ungauged tropical micro-watershed: a downscaling algorithm using GPM data. Water (switzerland) 12:1661. https://doi.org/10.3390/W12061661

Mayowa OO, Pour SH, Shahid S et al (2015) Trends in rainfall and rainfall-related extremes in the east coast of peninsular Malaysia. J Earth Syst Sci 124:1609-1622. https://doi.org/10.1007/ s12040-015-0639-9

Mo KC, Schemm JK, Juang HMH et al (2005) Impact of model resolution on the prediction of summer precipitation over the United States and Mexico. J Clim 18:3910-3927. https://doi.org/10. 1175/JCLI3513.1

Mohd MS, Daud D, Alias DB (2006) GIS Analysis for flood Hazard Mapping : Case study; Segamat. In: Seminar Nasional GIS: Geographic Information System Application for Mitigation in Natural Disaster. Jakarta, pp 1-15

Molteni F, Roberts CD, Senan R et al (2020) Boreal-winter teleconnections with tropical Indo-Pacific rainfall in HighResMIP historical simulations from the PRIMAVERA project. Clim Dyn 55:1843-1873. https://doi.org/10.1007/s00382-020-05358-4

Muqtada M, Khan A, Ashikin N, Shaari B et al (2014) Flood Impact Assessment in Kota Bharu Malaysia: A Statistical Analysis Faculty of Earth Science, Universiti Malaysia Kelantan, Jeli Campus, School of Quantitative Sciences, Universiti Utara Malaysia. World Appl Sci J 32:626-634. https://doi.org/10.5829/idosi.wasj. 2014.32.04.422

Nadrah N, Tukimat A, Harun S (2011) The projection of future rainfall change over Kedah, Malaysia with the statistical downscaling model. Malays J Civ Eng 23:67-79. https://doi.org/10.11113/ MJCE.V23N2.269

Ngai ST, Sasaki H, Murata A et al (2020) Extreme rainfall projections for malaysia at the end of 21 st century using the high resolution non-hydrostatic regional climate model (NHRCM). Sci Online Lett Atmos 16:132-139. https://doi.org/10.2151/SOLA.2020-023

Ngai ST, Tangang F, Juneng L (2017) Bias correction of global and regional simulated daily precipitation and surface mean temperature over Southeast Asia using quantile mapping method. Glob Planet Change 149:79-90. https://doi.org/10.1016/j.gloplacha. 2016.12.009

Nguyen-Thuy H, Ngo-Duc T, Trinh-Tuan L et al (2021) Time of emergence of climate signals over Vietnam detected from the CORDEX-SEA experiments. Int J Climatol 41:1599-1618. https:// doi.org/10.1002/joc.6897 
Noor M, bin Ismail T, Shahid S et al (2019) Selection of CMIP5 multimodel ensemble for the projection of spatial and temporal variability of rainfall in peninsular Malaysia. Theor Appl Climatol 138:999-1012. https://doi.org/10.1007/s00704-019-02874-0

Oh JH, Kim KY, Lim GH (2012) Impact of MJO on the diurnal cycle of rainfall over the western Maritime Continent in the austral summer. Clim Dyn 38:1167-1180. https://doi.org/10.1007/ s00382-011-1237-4

O'Neill BC, Kriegler E, Riahi K et al (2014) A new scenario framework for climate change research: the concept of shared socioeconomic pathways. Clim Chang 122:387-400. https://doi.org/ 10.1007/s10584-013-0905-2

Peatman SC, Matthews AJ, Stevens DP (2014) Propagation of the Madden-Julian Oscillation through the Maritime Continent and scale interaction with the diurnal cycle of precipitation. Q J R Meteorol Soc 140:814-825. https://doi.org/10.1002/qj.2161

Poli P, Hersbach H, Dee DP et al (2016) ERA-20C: an atmospheric reanalysis of the twentieth century. J Clim 29:4083-4097. https:// doi.org/10.1175/JCLI-D-15-0556.1

Qi W, Zhang C, Fu G et al (2016) Evaluation of global fine-resolution precipitation products and their uncertainty quantification in ensemble discharge simulations. Hydrol Earth Syst Sci 20:903920. https://doi.org/10.5194/hess-20-903-2016

Raghavan SV, Liu J, Nguyen NS et al (2018) Assessment of CMIP5 historical simulations of rainfall over Southeast Asia. Theor Appl Climatol 132:989-1002. https://doi.org/10.1007/ s00704-017-2111-z

Rashid HA, Hirst AC (2017) Mechanisms of improved rainfall simulation over the Maritime Continent due to increased horizontal resolution in an AGCM. Clim Dyn 49:1747-1764. https://doi. org/10.1007/s00382-016-3413-z

Rauscher SA, O'Brien TA, Piani C et al (2016) A multimodel intercomparison of resolution effects on precipitation: simulations and theory. Clim Dyn 47:2205-2218. https://doi.org/10.1007/ s00382-015-2959-5

Richter JH, Solomon A, Bacmeister JT (2014) Effects of vertical resolution and nonorographic gravity wave drag on the simulated climate in the Community Atmosphere Model, version 5. J Adv Model Earth Syst 6:357-383. https://doi.org/10.1002/2013M S000303

Saha S, Moorthi S, Pan HL et al (2010) The NCEP climate forecast system reanalysis. Bull Am Meteorol Soc 91:1015-1057. https:// doi.org/10.1175/2010BAMS3001.1

Salman SA, Nashwan MS, Ismail T, Shahid S (2020) Selection of CMIP5 general circulation model outputs of precipitation for peninsular Malaysia. Hydrol Res 51:781-798. https://doi.org/10. 2166/nh.2020.154

San-Martín D, Manzanas R, Brands S et al (2017) Reassessing model uncertainty for regional projections of precipitation with an ensemble of statistical downscaling methods. J Clim 30:203-223. https://doi.org/10.1175/JCLI-D-16-0366.1

Sato T, Miura H, Satoh M et al (2009) Diurnal cycle of precipitation in the tropics simulated in a global cloud-resolving model. J Clim 22:4809-4826. https://doi.org/10.1175/2009JCLI2890.1

Scher S, Haarsma RJ, de Vries H et al (2017) Resolution dependence of extreme precipitation and deep convection over the Gulf Stream. J Adv Model Earth Syst 9:1186-1194. https://doi.org/10.1002/ 2016MS000903

Siew JH, Tangang FT, Juneng L (2014) Evaluation of CMIP5 coupled atmosphere-ocean general circulation models and projection of the Southeast Asian winter monsoon in the 21 st century. Int $\mathbf{J}$ Climatol 34:2872-2884. https://doi.org/10.1002/joc.3880

Stevens B, Fiedler S, Kinne S et al (2017) MACv2-SP: a parameterization of anthropogenic aerosol optical properties and an associated. Geosci Model Dev 10:433-452. https://doi.org/10. 5194/gmd-10-433-2017

Stokstad E (1999) Scarcity of rain, stream gages threatens forecasts. Science (-80) 285:1199-1200

Syafrina AH, Zalina MD, Juneng L (2014) Future projections of extreme precipitation using Advanced Weather Generator (AWEGEN) over Peninsular Malaysia. In: IAHS-AISH Proceedings and Reports. IAHS Press, pp 106-111

Tan KC (2018) Trends of rainfall regime in Peninsular Malaysia during northeast and southwest monsoons. In: Journal of Physics: Conference Series. Institute of Physics Publishing, p 12122

Tan ML, Ficklin DL, Ibrahim AL, Yusop Z (2014) Impacts and uncertainties of climate change on streamflow of the johor River Basin, Malaysia using a CMIP5 general circulation model ensemble. J Water Clim Chang 5:676-695. https://doi.org/10.2166/wcc. 2014.020

Tan ML, Ibrahim AL, Duan Z et al (2015) Evaluation of six highresolution satellite and ground-based precipitation products over Malaysia. Remote Sens 7:1504-1528. https://doi.org/10.3390/ rs70201504

Tan ML, Ibrahim AL, Yusop Z et al (2017) Climate change impacts under CMIP5 RCP scenarios on water resources of the Kelantan River Basin, Malaysia. Atmos Res 189:1-10. https://doi.org/10. 1016/j.atmosres.2017.01.008

Tan ML, Liang J, Samat N et al (2021) Hydrological extremes and responses to climate change in the kelantan river basin, malaysia, based on the CMIP6 highresmip experiments. Water 13:1472. https://doi.org/10.3390/w13111472

Tangang FT, Juneng L, Salimun E, et al (2013) Projected precipitation changes over Malaysia by the end of the 21 st century using PRECIS regional climate model. In: Climate Change and Island and Coastal Vulnerability. Springer Netherlands, Dordrecht, pp 3-20

Tangang FT, Juneng L, Salimun E et al (2008) On the roles of the northeast cold surge, the Borneo vortex, the Madden-Julian Oscillation, and the Indian Ocean Dipole during the extreme 2006/2007 flood in southern Peninsular Malaysia. Geophys Res Lett 35:L14S07. https://doi.org/10.1029/2008GL033429

Tangang F, Chung JX, Juneng L et al (2020) Projected future changes in rainfall in Southeast Asia based on CORDEX-SEA multimodel simulations. Clim Dyn 55:1247-1267. https://doi.org/10. 1007/s00382-020-05322-2

Tangang F, Farzanmanesh R, Mirzaei A et al (2017) Characteristics of precipitation extremes in Malaysia associated with El Niño and La Niña events. Int J Climatol 37:696-716. https://doi.org/ $10.1002 /$ joc. 5032

Taylor KE (2001) Summarizing multiple aspects of model performance in a single diagram. J Geophys Res Atmos 106:7183-7192. https://doi.org/10.1029/2000JD900719

Tian Y, Peters-Lidard CD (2010) A global map of uncertainties in satellite-based precipitation measurements. Geophys Res Lett 37:24407. https://doi.org/10.1029/2010GL046008

Titchner HA, Rayner NA (2014) The Met Office Hadley Centre sea ice and sea surface temperature data set, version 2: 1 . sea ice concentrations. J Geophys Res 119:2864-2889. https://doi.org/ 10.1002/2013JD020316

Tompkins AM, Emanuel KA (2000) The vertical resolution sensitivity of simulated equilibrium temperature and water-vapour profiles. Q J R Meteorol Soc 126:1219-1238. https://doi.org/10.1002/qj. 49712656502

Varikoden H, Preethi B, Samah AA, Babu CA (2011) Seasonal variation of rainfall characteristics in different intensity classes over Peninsular Malaysia. J Hydrol 404:99-108. https://doi.org/10. 1016/j.jhydrol.2011.04.021

Varikoden H, Samah AA, Babu CA (2010) Spatial and temporal characteristics of rain intensity in the peninsular Malaysia using 
TRMM rain rate. J Hydrol 387:312-319. https://doi.org/10. 1016/j.jhydrol.2010.04.023

Volosciuk C, Maraun D, Semenov VA, Park W (2015) Extreme precipitation in an atmosphere general circulation model: Impact of horizontal and vertical model resolutions. J Clim 28:1184-1205. https://doi.org/10.1175/JCLI-D-14-00337.1

Wong CL, Venneker R, Uhlenbrook S et al (2009) Variability of rainfall in Peninsular Malaysia. Hydrol Earth Syst Sci Discuss 6:54715503. https://doi.org/10.5194/hessd-6-5471-2009

Wong CL, Liew J, Yusop Z et al (2016) Rainfall characteristics and regionalization in peninsular malaysia based on a high resolution gridded data set. Water (switzerland) 8:500. https://doi.org/10. 3390/w8110500

$\mathrm{Wu} \mathrm{CH}$, Hsu HH (2009) Topographic influence on the MJO in the maritime continent. J Clim 22:5433-5448. https://doi.org/10. 1175/2009JCLI2825.1

Xiang Soo EZ, Wan Jaafar WZ, Lai SH et al (2020) Evaluation of bias-adjusted satellite precipitation estimations for extreme flood events in Langat river basin, Malaysia. Hydrol Res 51:105-126. https://doi.org/10.2166/nh.2019.071

Xie S, Lin W, Rasch PJ et al (2018) Understanding cloud and convective characteristics in version 1 of the E3SM atmosphere model. J Adv Model Earth Syst 10:2618-2644. https://doi.org/10.1029/ 2018MS001350

Xin X, Wu T, Jie W, Zhang J (2021) Impact of higher resolution on precipitation over China in CMIP6 HighResMIP models. Atmosphere 12:762. https://doi.org/10.3390/atmos 12060762
Yang G-Y, Slingo J, Hoskins B (2009) Convectively Coupled Equatorial Waves in High-Resolution Hadley Centre Climate Models. J Clim 22(8):1897-1919. https://doi.org/10.1175/2008JCLI2630.1

Yang Q, Leung LR, Lu J et al (2017) Exploring the effects of a nonhydrostatic dynamical core in high-resolution aquaplanet simulations. J Geophys Res Atmos 122:3245-3265. https://doi.org/10. 1002/2016JD025287

Yashiro H, Kajikawa Y, Miyamoto Y et al (2016) Resolution dependence of the diurnal cycle of precipitation simulated by a global cloud-system resolving model. Sci Online Lett Atmos 12:272276. https://doi.org/10.2151/sola.2016-053

Yatagai A, Krishnamurti TN, Kumar V et al (2014) Use of APHRODITE rain gauge-based precipitation and TRMM 3B43 products for improving asian monsoon seasonal precipitation forecasts by the superensemble method. J Clim 27:1062-1069. https://doi. org/10.1175/JCLI-D-13-00332.1

Zhang Y, Zhou W, Leung MYT (2019) Phase relationship between summer and winter monsoons over the South China Sea: Indian Ocean and ENSO forcing. Clim Dyn 52:5229-5248. https://doi. org/10.1007/s00382-018-4440-8

Publisher's Note Springer Nature remains neutral with regard to jurisdictional claims in published maps and institutional affiliations. 